Est Ag 49 (2014) 363-399

\title{
Estudios en homenaje al profesor Rafael Navarro-Valls
}

\author{
P. Fernando CAmpo del Pozo OSA
}

RESUMEN: Se analizan en este trabajo los Estudios en homenaje al Profesor Rafael Navarro-Valls, que llevan por título: Religión, Matrimonio y Derecho. Se trata de temas interesantes y debates sobre el Matrimonio y la Religión dentro de nuestro entorno cultural con un amplio abanico de estudios elaborados por 174 juristas europeos y americanos que abordan muy diversos aspectos sobre la regulación del matrimonio y las figuras afines con las relaciones entre el Estado y la Iglesia, la religión cristiana y la integración de minorías islámicas en Europa. En estos dos gruesos volúmenes, con casi 4000 páginas, aparecen diversos aspectos y tendencias sobre la justicia, los derechos humanos, la libertad religiosa y los conflictos de conciencia. Hay temas de historia como lo referente a los canonistas agustinos españoles de los siglos XIV y XV que influyeron en su época. Se ha realizado homenaje por un equipo de buenos colaboradores, algunos formados por el profesor Rafael Navarro-Valls, cuya brillante trayectoria ha tenido muy en cuenta el matrimonio, la libertad religiosa, el Vaticano y la Casa Blanca (USA).

PALABRAS ClAVES: Derecho, matrimonio, religión, justicia y libertad religiosa

AbSTRACT: This is an analysis of the works in the homage to Professor Rafael Navarro Valls, with the title: "Religion, Marriage and Law." It contains interesting topics and debates on Marriage and Religion, within the cultural field of studies done by 174 European and American jurists, who took-up the various aspects of the regulation of marriage and topics related to the relations between State and Church, Christian religion and the integration of the Islamic minorities in Europa. These two thick volumes of nearly 4.000 pages, reveal the different aspects and opinions on justice, human rights and the conflicts of conscience. Included also here are other topics on history done by the Spa- 
nish Augustinian Canon Lawyer of the XIV and XV centuries, which had a significant impact on this epoch. The study has been prepared by a team of experts and directed by professor R. Navarro-Valls, under whose brilliant trajectory the themes marriage, religious freedom, the Vatican and the USA, are analysed.

KEY WORDS: Law, marriage, religions, justice and religious freedom.

\section{Introducción}

El día 6 de marzo de 2013 fue presentada la obra Religión Matrimonio y Derecho. Estudios en homenaje al profesor Rafael Navarro-Valls ${ }^{1}$, en la Academia de Jurisprudencia y Legislación en Madrid, con la asistencia de los presentadores, la mayoría de los colaboradores (174), miembros de la Academia y personas que habían manifestado su expresa adhesión al homenaje (160). Se llenó totalmente el local.

Intervinieron en la presentación el Excmo. Sr. D. Luis Díez Picazo y Ponce de León, Presidente de la Real Academia de Jurisprudencia y Legislación, y catedrático de Derecho Civil; D. Javier Martínez-Torrón, Director del Departamento de Derecho Eclesiástico UCM; D. Rinaldo Bertolini, Ex-rector de la Universidad de Turín y catedrático de Derecho Canónico; D. Rafael Puyol Antolín, catedrático de Geografía humana y Exrector de la Universidad Complutense de Madrid; D. Jorge de Esteban Alonso, Presidente del Consejo Editorial de El Mundo y catedrático de Derecho Constitucional; y el homenajeado, Excmo. Sr. D. Rafael Navarro-Valls, secretario de la Real Academia de Jurisprudencia y Legislación y catedrático de Derecho Eclesiástico del Estado. Todos ellos aportaron distintas facetas del homenajeado, que agradeció las alabanzas formuladas sobre sus aportaciones al Derecho y dio una breve explicación de su vida como profesor y canonista.

Los estudios del homenaje se recogen en dos gruesos volúmenes. Tiene muy buena presentación en cartoné forrado y es mejor su contenido de juristas europeos y americanos, algunos de connotado renombre, que abordan un variado abanico de reflexiones sobre el Matrimonio, la Religión y el De-

${ }^{1}$ J. Martinez-Turrón, S. Meseguer Velasco y R. Palomino Lozano (Coords.), Religión, Matrimonio y Derecho. Estudios en homenaje al Profesor Rafael Navarro-Valls, Iustel, dos volúmenes, Madrid 2013, 3.904 p. Se citará en adelante como Estudios en homenaje al Profesor Rafael Navarro-Valls. 
recho en sus diversos aspectos y problemas actuales con sus antecedentes y soluciones, algunas rayando la línea roja del más allá de lo jurídico-canónico en el siglo XXI.

Como se indica en la contraportada, esta edición ha sido posible gracias a la colaboración de la Dirección General de Universidades e Investigación de la Conserjería de Educación y la Comunidad de Madrid, al Departamento de Derecho Eclesiástico del Estado y al Grupo de Investigación "Religión, Derecho y Sociedad" de la Universidad Complutense y a la Fundación Caja-Murcia. Sus coordinadores Javier Martínez-Torrón, Silvia Meseguer Velasco y Rafael Palomino Velasco han sabido buscar colaboraciones y organizar el plan de la obra en una época de crisis económica, por lo que se les dan las gracias, a los patrocinadores, como a la Editorial Iustel, y particularmente al Presidente de su Consejo Editorial, Santiago Muñoz Machado por las facilidades dadas para la publicación de estos dos volúmenes con la superación de no pocas dificultades. Los nombres de algunos de sus colaboradores aparecen al final de la "Presentación" dejando constancias de que han tenido ocasión de beneficiarse del magisterio de Rafael Navarro-Valls en la Universidad Complutense ${ }^{2}$.

Desde el año 2009 han estado trabajando los coordinadores y sus colaboradores para la elaboración de los estudios y el empaquetamiento en dos volúmenes. En el volumen primero se recogen los estudios sobre Religión y Derecho con este orden: $1^{\circ}$ Relaciones entre Estado y Religión. $2^{\circ}$ Principios constitucionales y libertad religiosa. $3^{\circ}$ Conflictos entre conciencia y ley. $4^{\circ}$ La gestión pública del pluralismo religioso, y $5^{\circ}$ Derecho comparado. En vol. II $^{\circ}$ están los estudios que tratan del Derecho Matrimonial, Derecho Canónico y otras especialidades jurídicas con sus diversos contenidos. Derecho Matrimonial: $1^{\circ}$ Derecho matrimonial canónico y $2^{\circ}$ Matrimonio familia y Derecho. Derecho Canónico: $1^{\circ}$ Estudios históricos y $2^{\circ}$ Cuestiones varias de Derecho Canónico. Otras especialidades: $1^{\circ}$ Derechos fundamentales y Derecho Constitucional y $2^{\circ}$ Estudios jurídicos varios. Concluye la obra con un Epílogo: "La obra divulgadora de un canonista" por Jorge de Esteban, que le presenta como su maestro y formador de una especie de escuela con nuevos horizontes para el Derecho Canónico o como ahora se dice Derecho Eclesiástico del Estado en España, donde Rafael Navarro-Valls, es Catedrático Emérito de la Universidad Complutense ${ }^{3}$.

${ }^{2}$ Ibíd., p. 33.

${ }^{3}$ Ibíd., II, pp. 3764-3769. Este artículo es una nueva versión corregida y aumentada, con referencias bibliográficas a su intervención en el acto de presentación el día 21 de enero de 2011 del libro de R. NAVArro-Valls, Entre la Casa Blanca y el Vaticano, Ediciones Internacionales Universitarias, Madrid 2000, 357 pp. 


\section{Currículo de Rafael Navarro-Valls y sus primeras publicaciones}

Rafael Navarro-Valls nació en Cartagena (España) el 12 de febrero de 1940 dentro de una familia de cinco hermanos. Su padre era abogado del Estado. Cursó sus primeros estudios en la ciudad natal y luego en Murcia para seguir la carrera de Derecho, que culminó en 1962 con el Premio Extraordinario de Licenciatura. Tuvo como profesor y mentor a D. Mariano López Alarcón, que había nacido en Murcia en 1917 y murió en 2009. Influyó mucho en su vida universitaria.

Cursó los estudios de Derecho Canónico en la Universidad de Navarra donde obtuvo la Licenciatura canónica en 1965, al mismo tiempo que era Director del Colegio Mayor Universitario (Belagua). Se relacionó en Pamplona con el benemérito profesor Pedro Lombardía, que murió en 1986, dejando formada una escuela de buenos canonistas y eclesiasticistas. Pasó luego Rafael Navarro-Valls a Zaragoza para ser Director del Colegio Mayor (Miraflores), donde demostró sus dotes de dirección y de gobierno, al mismo tiempo que concluía su tesis doctoral. La defendió cum laude en la Universidad de Navarra en 1967. Ese mismo año se trasladó a Madrid, para encargarse de la Dirección del Colegio Mayor Moncloa, unido a la Universidad Complutense, donde comenzó pronto a ser profesor ayudante de Derecho Canónico en la facultad de Derecho, al lado de su amigo el catedrático D. Mariano López Alarcón, que le ofreció luego un puesto docente en 1971 en la universidad de Murcia, donde permaneció hasta 1975. Ese año hizo oposiciones a la cátedra de Derecho Canónico en la Universidad Complutense y en ella va a continuar hasta el presente. Al ser hermano de Joaquín Navarro-Valls, corresponsal de ABC en Roma y portavoz del Vaticano le llevará a realizar estudios especiales sobre el Vaticano y la Casa Blanca con análisis de la actuación de la Santa Sede en materia concordataria.

Entre sus primeras publicaciones están: "Convergencia concordataria en el Accord-normatif” en Jus Canonicum, 9 (1965) 141-153.

"Los representantes diplomáticos de la Santa Sede según la última legislación canónica", en Revista Española de Derecho Internacional. 2-3 (1970) 90-100.

"La licencia en la enajenación canónica y el derecho español", en Jus Canonicum, 10 (1970) 303-391.

"Reflexiones sobre los condicionamientos del ordenamiento canónico", en Revista de la Facultad de Derecho de la Universidad de Murcia (1970-1971) 5-39. 
"Estatuto personal islámico y divorcio vincular", en Revista Española de Derecho Canónico, 79-81 (1972) 363- 389.

Divorcio: orden público y matrimonio canónico. Eficacia en España de las sentencias extrajeras de divorcio, Ed. Montecorvo, Madrid 1972,

"Jurisprudencia española ante el divorcio vincular", en El Fenómeno religioso en España. Madrid 1973, pp. 237-303.

"Forma jurídica y matrimonio canónico", en Jus Cononicum 27 (1974) 64-108.

Le conocía por sus escritos, especialmente a partir de 1974 y en la segunda etapa de su docencia desde 1975 en la Universidad Complutense, donde se va a convertir en un especialista en Derecho matrimonial.

\section{Cómo comencé a conocer y tratar al profesor Rafael Navarro-Valls}

Le llegué a conocer y tratar personalmente en Andorra, con motivo de la XV Semana Internacional de Derecho Canónico sobre "el consentimiento matrimonial," celebrada del 16 al 21 se septiembre de 1974. Allí tuvo él una conferencia el día 20, viernes, por la tarde, sobre "La expresión legal de consentimiento" a la luz del Derecho vigente y del proyecto del Derecho matrimonial, cuyo esquema procuramos conseguir los que asistíamos mediante copias bajo cierto secreto profesional.

En el proyecto del nuevo Derecho Canónico se dejaba a las Conferencias Episcopales cierta facultad para elaborar el rito de acuerdo con los usos y costumbres del lugar, con aprobación de la Sede Apostólica, conservando el espíritu cristiano y la asistencia del ministro sagrado que debía pedir y recibir el consentimiento para constancia de la celebración del sacramento.

En cuanto a la forma, se presentaban problemas en no pocos países de África, Asia y América. Algunos manifestaron que en ciertos lugares convendría dar valor religioso a la manifestación de los contrayentes católicos ante el juez civil, que se encargaría de proteger la institución matrimonial. La autoridad civil de ciertos países acapara la materia matrimonial. Se alegó que en Venezuela tenían que casarse antes por lo civil y luego por la iglesia si querían. Al casarse civilmente manifestaban su deseo de unirse para siempre y cumplir con los bienes del matrimonio. Se recordó que ya existieron problemas con los ritos chinos y antes al evangelizar a los aborígenes de América. Así en Michoacán, México, el P. fray Alonso de Veracruz se encontró con tres formas distintas de contraer matrimonio, que menciona su 
Speculum coniugiorum. Esta obra matrimonial tuvo tres ediciones en el siglo XVI, la primera en Méjico el año 1556, luego en Salamanca 1562 y finalmente en Milán en 1599. En esta edición se añadió el Apéndice, donde recogía la doctrina de Trento y algunos privilegios que, como opúsculo complementario, había sido publicado en Alcalá de Henares en 1572. Esto le llamó la atención al buen profesor D. Lamberto de Echeverría, que recordó el problema de los ritos chinos y los privilegios para los matrimonios en el Nuevo Mundo. Merecía la pena recordar a fray Alonso de Veracruz, como antiguo profesor salmantino, cuyas obras había editado el jesuita Ernes J. Burrus en varios tomos ${ }^{4}$.

En cuanto a los matrimonios clandestinos, fray Alonso de Veracruz opinaba que eran válidos, aunque alguno opinase lo contrario, al que refuta sin mencionar su nombre, precisando que había dos clases de matrimonios clandestinos: $1^{\mathrm{o}}$ los celebrados sin testigos y $2^{\circ} \sin$ amonestaciones ${ }^{5}$. También había matrimonios con ritos especiales en Nueva Granada y Perú, que relatan Antonio de la Calancha y Bernardo de Torres con una especie de velación y fiestas ancestrales.

Rafael Navarro-Valls se interesó por la doctrina de san Agustín y la opinión de fray Alonso de Veracruz sobre esta materia. Se alegró al saber que para solucionar la enmarañada problemática del matrimonio, A. de Veracruz, por mediación de Felipe II, logró una Constitución de San Pío V, Romani Pontificis, del 2 de agosto de 1571, por la que se autorizaba, al infiel que se convertía y tenía varias mujeres, a quedarse con la que se hubiese bauzado antes o una de las que se bautizan con él, porque solía quedarse con la más joven o preferida. Esta Constitución se divulgó en el Speculum coniugiorum de fray Alonso de Veracruz, que consideró a veces disoluble el matrimonio consumado y natural de los infieles, porque podía interesar al orden público de la Iglesia?

Este problema y la solución dada por fray Alonso de Veracruz, la relata ampliamente fray Juan de Grijalva cuando nos dice que el bautismo se dilataba, a veces, cuando se quería saber cuál era la primera mujer bautizada

${ }^{4}$ E. J. BurRus, The Writings of A. de Veracruz, 5 vols., Roma 1968-1976.

${ }_{5}^{5}$ A. DE Veracruz, Speculum Coniugiorum, pars 1a, art.10, Milán 1599, p. 34. Puede verse cómo se casaban los jóvenes de Michoacán según fray Alonso de Veracruz en la traducción castellana por A. GÓMEZ CANEDO, El magisterio filosófico y jurídico de Alonso de Veracruz, México, 1984, pp. 61-62.

${ }^{6}$ A. DE la Calancha y B. De Torres, Crónicas Agustinas del Perú, ed., Por Manuel Merino, I, Madrid 1972, pp. 178-179. F. CAMPO DEL Pozo, Los Agustinos en la Evangelización de Venezuela, Caracas 1979, pp. 254-260.

${ }^{7}$ A. DE VeracruZ, Speculum Coniugiorum, pars II, art. 28 y 29, pp. 2677-2778. F. J. HerNÁEZ, colección de Bulas, Breves y otros documentos relativos a la Iglesia en América Latina y Filipinas, I, Bruselas 1879, p. 55. 
ya que todas ellas querían seguir con el marido y él solía seguir apegado a la segunda o a la más joven ${ }^{8}$.

En la actualidad, ante los problemas que se presentaban en los coloquios, D. Lamberto se preguntaba: ¿Qué hacer entonces? Las respuestas no son siempre fáciles para zanjar los problemas en cuanto a la fórmula matrimonial ${ }^{9}$.

Seguí comunicándome con el profesor Rafael Navarro Valls sobre la doctrina de san Agustín y algunos agustinos, como Basilio Ponce de León, sobrino de fray Luis de León y gran teólogo, que sobresalió por su opinión sobre el consentimiento matrimonial, del que depende el fieri del matrimonio, refutando la doctrina del jesuita Tomás Sánchez, cuyo texto se sobrepuso al de fray Alonso de Veracruz en el siglo XVII. El tiempo y el nuevo esquema del Derecho matrimonial, según D. Tomás García Barberena, han venido a darle la razón a Basilio Ponce de León, de quien tomó algunas ideas para ambientar el desarrollo de la Semana ${ }^{10}$.

D. Lamberto de Echeverría hizo un resumen al final de la semana resaltando algunas conclusiones a las que se había llegado para salvaguardar al matrimonio cristiano tal como aparece en el Evangelio. La tradición y el magisterio eclesiástico nos lo presentan corrigiendo errores que van surgiendo a lo largo de la vida, como ha sucedido en cuanto a la forma del matrimonio sin una buena preparación ${ }^{11}$. Sobre la forma del matrimonio en la actualidad hay dos buenos estudios en el homenaje a Rafael Navarro Valls, uno de José Luis Santos sobre: "El abandono formal de la Iglesia y la norma canónica del matrimonio. M. Pr. Omnium in mentem"12 y otro de Carlos Seco Caro sobre: "La dispensa de la forma de celebración del matrimonio" ${ }^{13}$. Sigue siendo problemático el matrimonio en ciertas regiones de América latina, como aparece en la interesante colaboración de José Luis Llaquet de Entrambasaguas, "El matrimonio indígena andino," 14 donde se menciona la bula de Pablo III, "Altitudo divini consilii de 1537 y la de Pío V, Romani Pontificis del 2 de agosto de 1571, sin mencionar a fray Alonso de Veracruz y observando que "algunos sacerdotes intentaron restringirlo

${ }^{8}$ J. DE GRIJALVA, Crónica de la Orden de San Agustín de Nuestro Padre San Agustín en las provincias de Nueva España, México 1624, f. 13, col.1.

${ }^{9}$ F. CAMPO DEL Pozo, "XV Semana Internacional de Derecho Canónico sobre el consentimiento matrimonial en Andorra", en Estudio Agustiniano 9 (1974) 488.

${ }^{10}$ Ibíd., pp. 476-477. T. SÁNCHEZ, Disputatiomum de sancto matrimonii sacramento, Genue (Génova) 1602; De matrimonio, Madrid 1623. Se impuso esta obra como texto sobre el matrimonio en el s. XVII.

${ }^{11}$ Ibíd., p. 490.

${ }^{12}$ Estudios en homenaje al Profesor Rafael Navarro-Valls, II. pp. 2035-2040.

${ }^{13}$ Ibíd., pp. 2047-2073.

${ }^{14}$ Ibíd., pp. 2325-2340. 
considerando que el privilegio sólo procedía cuando no fuera posible reconocer la primera mujer o cuando ésta estuviese ausente o no aceptase convertirse ella misma" ${ }^{15}$. La cuestión era que solían bautizarse todas para seguir siendo sus esposas, por lo que se le daba facultad al esposo para escoger la que quisiese. Había que tener en cuenta sus costumbres y procurar cristianizarlas, como sucedía con el sirvinakuy, preincaico con unos ritos simbólicos, que llegaron a celebrarse ante sacerdotes con ánimo de cumplir verdadero matrimonio los contrayentes, una vez bautizados. En Bolivia se reconoce determinados derechos a la praxis del sirvinakuy, como "pareja de hecho" ${ }^{16}$. Quedan aún bastantes pueblos indígenas en los Andes y en otras regiones que se rigen por unas costumbres propias, que apenas han evolucionado en cuanto a institución matrimonial y aspiran a que se les reconozcan jurídicamente.

\section{Siguió el diálogo sobre la doctrina agustiniana y el porqué de esta cola- boración}

Seguí comunicándome con el profesor Rafael Navarro-Valls, en cuanto a la doctrina de san Agustín, sobre los tres bienes del matrimonio: el de la prole, la fidelidad (desde la fe) y el sacramento ${ }^{17}$. Para san Agustín era fundamental la fe, porque sin ella no hay sacramento. Consideraba a la familia como base y una partícula de la sociedad con un gran valor religioso y social $^{18}$. Esto nos llevó a un intercambio de cartas porque le interesaba ampliar sus conocimientos, aunque estaba bastante bien informado.

San Agustín consideró al matrimonio como un bien y lo expuso especialmente al comentar el Génesis, donde hace un resumen de su doctrina: "El bien del matrimonio descansa sobre la triple base de la fidelidad, de la prole y del sacramento. La fidelidad impone que los esposos mantengan incólume la fe prometida y que no se rompa el vínculo conyugal prevaricando con otro o con otra. La prole exige que se la reciba con espíritu de amor, se la críe y sustente con diligencia y bondad, y se la eduque religiosamente. El

${ }^{15}$ Ibíd., p. 2324"

${ }^{16}$ Ibíd., pp. 2329-2335. Se requería un conocimiento previo y hasta convivencia. Intervenían los padres y se ponían condiciones. Se detallan los ritos propios de aquella época que en parte subsisten.

${ }^{17}$ SAn Agustín, Del bien del matrimonio, 24, 32. Traducción por Félix García, Obras de San Agustín, BAC, 12, Madrid 1954, pp.112-115.

${ }^{18}$ De civitate Dei, 1 y lib. 19, cap. 14-. Traducción de José Morán, Obras de San Agustín, BAC, 17, Madrid 1958, pp. 1405-1406. F. CAMPO DEL Pozo, Filosofía del Derecho según San Agustín, Valladolid 1966, pp. 163-168. 
sacramento pide que los esposos no se separen jamás, y que, en caso de separación, ni el uno ni la otra se vinculen de nuevo, ni aun con el fin único de tener descendencia. Estos tres puntos constituyen la norma del matrimonio, en el cual se dignifica la fecundidad de la naturaleza y se refrena la depravación de la incontinencia"19.

San Agustín trató sobre el matrimonio desde un punto de vista biológico que se apoya en la atracción y se justifica por la procreación. Un segundo aspecto es el religioso y social con una comunidad fundamentada en el amor, que es lo más sublime del matrimonio con los otros valores que le adornan: el bien de la fidelidad y el del sacramento que influyen en el orden religioso de la Iglesia y en el orden social del Estado. San Agustín auspició la formación de un Estado cristiano como afirmó en una de sus cartas: "Si la Religión Cristiana se entendiese como debiera, establecería, consagraría, y engrandecería una República mejor que lo que supieron hacer Rómulo, Numa, Bruto y otros hombres ilustres"20.

Esa República cristiana, como civitas, equivale a una comunidad o multitud de hombres unidos entre sí mediante una ordenada concordia ${ }^{21}$. San Agustín fue el primero en hacer una Filosofía y Teología de la Historia. Si hizo un gran aporte a la Filosofía con los conceptos de bien común y de comunidad, realizó mayores aportes a la Teología con su doctrina sobre la gracia y la eclesiología cristológica. Según san Agustín, la iglesia visible e histórica es al mismo tiempo participación de la comunidad celeste. El sujeto de las acciones sacramentales es propiamente Jesucristo, que se hace viviente como cabeza de la Iglesia en la acción sacramental del matrimonio. La iglesia aparece como instrumento de salvación para todos los hombres en La Ciudad de Dios con la dimensión profético-escatológica. Esto es algo que conviene tener en cuenta en la docencia universitaria del Derecho Canónico, en cuyas normas, hay que ver lo que Cristo nos manda actualmente como observó el Dr. fray José López Ortiz en "Prólogo" al Código de Derecho Canónico: "Está Cristo detrás de él"22.

La doctrina de san Agustín fue vertebradora de la cultura de la edad media, especialmente por los canónigos regulares, que se consideraban de su Orden. Uno de ellos, el papa Gelasio, que gobernó a la iglesia entre el año

${ }^{19}$ San Agustín, De Genesi ad litteram, lib. 9, cap. 7, n. 12. Traducción por Balbino Martín, Obras de San Agustín, BAC, 15, Madrid 1957, pp. 1020-1021.

${ }^{20}$ SAn Agustín, Epístola 138 a Marcelino, cap. 2, n. 10. Traducción por Lope Cilleruelo, en Obras de San Agustín, BAC, 11 Madrid 1953, p. 135.

${ }^{21}$ Ibíd., p. 134. "Quid est autem civitas, nisi multitudo hominum in quodam redacta concordiae".

22 J. López OrTíz, “Prólogo” al Código de Derecho Canónico de 1917, 8ª edic. BAC, Madrid 1969, p. XXX. 
492 y 496, siguiendo la doctrina de san Agustín, escribió una carta al emperador Anastasio "Duo sunt quippe", donde formuló las tres ideas que rigen la Cristiandad y la sociedad medieval: $1^{\text {a }}$ la distinción de poderes, espiritual y temporal, aunque a veces los podía tener una persona como el papa; $2^{\mathrm{a}}$ deber de colaboración entre ambos poderes y $3^{\text {a }}$ superioridad del poder espiritual, al menos por razón del pecado ${ }^{23}$. Estas tres ideas o principios son admitidos por los canonistas en la edad media. Sobre esto hay un buen estudio en el homenaje a Rafael Navarro-Valls, por Jesús Bogarín Díez con este título: "La fórmula gelasiana según las traducciones ${ }^{24}$. Aunque hay distintas traducciones del texto latino en todas ellas se reconoce la distinción del poder temporal o civil y el espiritual (eclesiástico), con una superioridad del poder espiritual, al que se une el "bien común, que debe predominar sobre el particular". Una de las mayores aportaciones de san Agustín a la Filosofía y al Derecho.

Era canónigo regular san Pedro Damiano, el asesor principal de Gregorio VII, como lo fue también san Ivo de Chartres, el patrono de los abogados. Fueron canónigos regulares de san Agustín los papas León VIII, Alejandro II, Pascual II, Lucio II, Alejandro III, Inocencio III y Honorio III, cuya lista nos da Rafael Volaterrano ${ }^{25}$.

El papa Alejandro III, que había sido profesor de Derecho Canónico en Bolonia con el nombre de Rolandus Bandinelli, defendía que el verdadero matrimonio era el consumado, al llegar a ser papa, le preguntaron si era verdadero matrimonio con el sólo consentimiento, como se defendía en la Universidad de París. Respondió con una solución ecléctica y un poco salomónica diciendo que "el matrimonio con el sólo consentimiento como se defendía en la Sorbona de París era verdadero matrimonio y podía ser disuelto por el papa, pero el consumado según la escuela de Bolonia, ni por el papa". De ahí que surgiese el refrán de que a los niños los trae la cigüeña de París. No hay una solución definitiva.

San Agustín ha estado presente en la doctrina de la Iglesia especialmente en el Corpus Iuris Canonici, donde hay más de 500 citas de sus obras. Se encuentra aún vivo su pensamiento en sus escritos, por lo que da la impresión de que, aunque sea de hace más de mil seiscientos años, se le siente como un hombre moderno, según José Ortega y Gasset ${ }^{26}$. El obispo de Hi-

${ }^{23}$ GELASIO "Epístola 8 ad imperatorem Anastasium", PL, 60, col. 42.

${ }^{24}$ Estudios en homenaje a Rafael Navarro-Valls, II, pp. 2599-2633.

${ }^{25}$ R. Volaterrano, Historia Canonicorum Regularium, Ms. f. 3. Se encuentra en el Archivo del Pilar, Zaragoza, almanaque 1, caja 7, lig. 1, n. 3.

${ }^{26}$ J. ORtega y Gasset, Obras completas, IV, Madrid 1947, p. 28. 
pona nos habla, como un amigo, con una frescura y actual, procurando conciliar la razón y la fe en busca de la verdad. Fue un buscador de la verdad, de la justicia y de la paz, incluso de la dignidad del hombre y de su libre albedrío o libertad. La doctrina de san Agustín fue defendida especialmente por los canónigos regulares, como Hugo de San Víctor y por otros autores de su Orden mendicante, que dan materia no sólo para el "Agustinismo Político" sino para otros muchos temas pendientes de estudio.

Para participar en el menaje al profesor Rafael Navarro-Valls se prescindió de los canónigos regulares y se pensó en los canonistas agustinos españoles de los siglos XIV y XV, porque los había estudiado dando a conocer algunos de sus escritos. Tuvieron como antecedente además de san Agustín, a Egidio Romano y a otros canonistas italianos, los principales defensores del papado en el siglo XIV, "por lo que fueron nombrados sacristas del papa por Juan XXII". El sacrista era obispo y Vicario del Vaticano, cargo que se conservó desde 1352 hasta 1968. El último fue el agustino holandés P. Canisio van Lierde. Siguen los agustinos hoy con la sacristía del Vaticano y la parroquia de Santa $\mathrm{Ana}^{27}$.

\section{Escuela Agustiniana con Egidio Romano y otros teólogos-canonistas}

Después de san Agustín, se considera a Egidio Romano o Gil de Roma, como el principal representante de la Escuela Agustiniana en la Edad media con su tratado De regimine principum, escrito hacia el año $1280 \mathrm{y}$ dedicado al rey de Francia, Felipe el Hermoso, muy amigo de la familia Colonna, a la que pertenecía Egidio. En este libro se trazan los delineamientos de la doctrina teocrática del Agustinismo Político ante el Estado dinástico, refutando las nuevas estructuras nacionales y laicistas, que rozaban y hasta chocaban contra la doctrina de la Iglesia, aunque él procuró conciliar el poder espiritual con el temporal. Dividió su obra en tres partes. En la primera parte trata del príncipe cristiano, con sus circunstancias, su vida moral, derechos y obligaciones. En la segunda parte, explica la doctrina sobre la vida del príncipe en familia, dentro de la comunidad y cómo debe actuar también en la sociedad. Y en la tercera, expone la doctrina política y canónica sobre el gobierno de los príncipes respecto de sus súbditos y las ciudades, que componen su reino de acuerdo con la doctrina cristiana,

${ }^{27}$ F. CAMPo DEL Pozo, "Defensores del Papa”, en Casiciaco, Valladolid, n. 108 (1956) 161-164, donde se observó que por ese motivo se nombró a un agustino "Sacrista del Papa". 
bajo la autoridad del papa, admitiendo más bien el poder indirecto. Se le considera coautor de la bula Unam Sanctam de Bonifacio VIII ${ }^{28}$.

De regimine principum fue bien recibido y traducido a los distintos idiomas, como el castellano, por lo que se encuentran varios manuscritos e incunables, como el existente en la Biblioteca de la Universidad de Salamanca, con este título: "Del regimiento de los Príncipes, hecho y ordenado por el Dr. Fray Gil de Roma, de la Orden de san Agustín. E hízolo trasladar del latín al romance Bernardo, obispo de Osma, por D. Juan García de Castrogeriz, por honra y enseñamiento del muy noble D. Pedro primero y heredero del muy alto y muy noble D. Alfonso Rey de Castilla, de Toledo, de León", etc. ${ }^{29}$ A Egidio Romano le siguen Alejandro de San Elpidio, Agustín Triunfo, Santiago de Viterbo y otros defensores del papado y de la potestad indirecta, admitiendo también, a veces, el poder temporal directo, ya que el poder temporal está sometido en parte al espiritual con el "dominium universale", que se ejerce "per executionem et administrationem" 30. Los juristas agustino-italianos de la edad media han sido bastante bien expuestos por Hugo Mariani, Adolar Zumkeller y otros, que recapitulan sus principios en estos términos: $1^{\circ}$ la potestad sacerdotal del Romano Pontífice, que le viene directamente de Dios, es superior a la potestad regia; $2^{\circ}$ el papa puede juzgar y deponer al rey, si no cumple con sus deberes y se porta mal; $3^{\circ}$ las cosas temporales están sometidas directa o indirectamente al papa; $4^{\circ}$ la potestad de la Iglesia es universal y superior a la de los laicos; $5^{\circ}$ el papa es el juez supremo de la Iglesia y tiene jurisdicción sobre los litigios entre los cristianos; $6^{\circ}$ el poder eclesiástico tiene capacidad de poseer y tener bienes para cumplir su fin; $7^{\circ}$ se reconoce el poder secular y las dos espadas. Se puede pedir la ayuda del poder secular en algunos casos, etc. ${ }^{31}$

$\mathrm{Al}$ admitirse el predominio del bien común sobre el particular, se dio apoyatura al Derecho de Gentes en la Cristiandad medieval, creando vínculos éticos y jurídicos entre las naciones, algo que se desarrollará mejor en el siglo XVI por la Escuela Española, como lo ha expuesto el P. Lucas García, que pensó escribir dos tomos sobre los juristas y políticos agustinianos pero se quedó en un simple proyecto ${ }^{32}$. La doctrina de la potestad di-

${ }^{28}$ De regimine principum III, p. 1, c. 5. Cf. R. ScHOLZ, Umbekante Kirchenpolitische Streischriften aus der Zeit Ludwig des Bayer, II, Roma 1914, p. 9

${ }^{29}$ Del Regimiento de los Príncipes, editado por Maynardo Urgaut y Stanislao Polo, Sevilla 1494.

${ }^{30}$ A. DE AnConA, Summa de potestate eclesiástica, q. 1, a.1, Roma 1582, p. 2.

${ }^{31}$ A. Zumkeller, "De doctrina sociali scholae augustiniani Aevi Medii" en Analecta Augustiniana, 22 (1951) 57-84; H. MARIANI, Chiesa e Statu nei teologi agostiniani del secolo XIV, pp. 147-151; L. GAGO, Trayectoria histórica de la Escuela Agustiniana, Bogotá 1963, p. 100.

${ }^{32}$ L. GARCíA, La paz y la guerra. Luis de Molina y la Escuela Española del siglo XVI en relación con la ciencia y el Derecho Internacional Moderno, Zaragoza 1944, pp. 7 y 264, donde 
recta e indirecta del papa, que era considerado monarca universal de todo el mundo: "universalis monarcha totius populi christiani et de iure totius mundi," repercutió en las relaciones internacionales de la santa Sede en los siglos XIII y XV y después en la evangelización del Nuevo Mundo, como ha puesto de relieve el profesor José Antonio Tomás Ortiz de la Torre, en su trabajo titulado: "Algunas notas históricas sobre la presencia de la Santa Sede en las relaciones internacionales de España" ${ }^{33}$.

Algo de esto logró aclarar Bonifacio Díez Fernández con algunos estudios jurídicos de la Orden Agustiniana y el concepto del Derecho natural y el Derecho positivo según los clásicos agustinos españoles del siglo $\mathrm{XVI}^{34}$. Avanzó más Manuel Villegas, con un ensayo bibliográfico sobre los "Teólogos agustinos pre-tridentinos", entre los que se incluyen algunos canonistas de los siglos XIV y XV, limitándose a mencionar sus escritos ${ }^{35}$. Hay algunos estudios particulares, que se irán citando, porque hacen referencia al Derecho canónico y jurídico, junto con la Moral. Así como estuvo la Teología mezclada con el Derecho canónico hasta el siglo XII, de igual manera llegó a darse cierta relación de la Teología y la Moral con el Derecho por la Escolástica y los juristas hispanos y de toda Europa, como puso de relieve Samuel Pufendorf, exigiendo una separación del Derecho y la Moral con una nueva actitud metódica al tratar del Derecho natural, dominante en los canonistas y juristas hispanos, incluso en Alemania, hasta el siglo XVI, y aun después ${ }^{36}$.

Hay algunos filósofos y teólogos agustinos de la edad media que han tratado incidentalmente algún tema del Derecho, como el referente al Derecho natural y la justicia, especialmente en Salamanca. Éstos últimos han sido más estudiados ${ }^{37}$. Conviene observar que casi todos los que han tra-

se afirma en nota: "En preparación: Ideas jurídicas, políticas y sociales de la Escuela Agustiniana. (Dos tomos de unas 400 páginas cada uno)."

${ }^{33}$ Estudios en homenaje al Profesor Rafael Navarro-Valls, II, pp. 27-95-2800.

${ }^{34}$ B. Díez Fernández [DIFERNAN], "La Orden Agustiniana y los estudios jurídicos en la época clásica española" en Anuario de Historia del Derecho, 25 (1955) 775-790; y "Estudio de Derecho natural y Derecho positivo según los clásicos agustinos españoles del siglo XVI", en La Ciudad de Dios, 169 (1956) 253-284.

${ }^{35}$ M. VILlegas, “Teólogos agustinos españoles pre-tridentinos", en Repertorio de Historia de las Ciencias Eclesiásticas en España, 3, Salamanca 1971, pp. 321-359. En este trabajo se da la bibliografía general con los estudios especiales en las pp. 223-226. El mismo autor ha elaborado una buena biografía titulada: Fray Bernardo Oliver (1280?-1348) primer obispo agustino español, Editorial Revista Agustiniana, Madrid 2013. El manuscrito mecanografiado pasa de las $100 \mathrm{pp}$.

${ }^{36}$ F. CAMPO DEL Pozo, "Metodología jurídico canónica según S. Pufendorf”, en Estudio Agustiniano, 24 (1989) 713-729.

${ }^{37}$ E. Domínguez carretero, "La Escuela Teológica Agustiniana de Salamanca”, en La Ciudad de Dios, 169 (1956) 638-685. 
tado temas de Derecho canónico fueron también biblistas, como sucedió con Bernardo Oliver, Juan de Alarcón, promotor de la observancia religiosa, como luego veremos, y otros. Se estudia aquí a cuatro autores: Bernardo Oliver, Francisco Castelló, Juan de Alarcón y Martín de Córdoba, haciendo un breve análisis de sus escritos, que se han dado a conocer en estos últimos años. Se mencionará a otros que no dejaron escritos. El número de agustinos, que trataron temas de Derecho, aumentó en el siglo XVI, con teólogos que fueron al mismo tiempo canonistas y biblistas como Alfonso de Córdoba, Juan de Guevara, Alonso de Veracruz, Pedro de Aragón, san Alonso de Orozco y fray Luis de León, que escribió un Tratado sobre las leyes y se dio cuenta de que se aplicaba un Derecho antiguo para un mundo moderno, etc. La orientación político-teológica de algunos canonistas y juristas agustinianos de los siglos XVI y XVII originó acusaciones infundadas por parte de los molinistas, que motejaron a Basilio Ponce de León, Cristiano Lupo y Enrique Noris de jansenistas, "quesnelianos" y regalistas $^{38}$.

\section{Fray Bernardo Oliver y sus "Concordantiae decretorum cum Biblia"}

Fray Bernardo Oliver (1280?-1348) llegó a ser el primer obispo agustino en España y fue embajador del rey de Aragón ante el papa. Se le puede considerar como el primer canonista y decretista de los agustinos españoles y uno de los representantes más conspicuos de la canonística medieval, dentro de la Escuela Agustiniana, al procurar dar una fundamentación bíblica y teológica al Derecho. A pesar de su categoría intelectual, jerárquica y teológica pasó casi desapercibido en las historia de la Orden de san Agustín hasta que el benemérito historiador, Jerónimo Román, reconoció sus méritos como obispo y autor de obras notables ${ }^{39}$.

Aparecía su nombre en la Crónica del rey de Aragón, Pedro IV, ante el que medió para promover la paz, lo mismo que ante la curia pontifica desde el pontificado de Juan XXII hasta Clemente VI, que le consideraba digno de reconocimiento por sus méritos el 12 de enero de 1345, ya que se

\footnotetext{
${ }^{38}$ M. F. MiguÉLEZ, Jansenismo y Regalismo en España, Valladolid 1895, pp. 21-85; F. CAMPo DEL Pozo, "Influencia del Derecho medieval en fray Luis de León", Pensamiento Medieval Hispano, Homenaje a Horacio Santiago-Otero, Madrid 1998, pp. 1359-1381.

${ }^{39}$ J. Román, Chrónica de la Orden de los Ermitaños del glorioso Padre Sancto Augustín, Salamanca 1569, f. 67r, donde aparece copia de la Crónica del rey de Aragón Pedro IV, añadiendo que había llegado a ser cardenal con el título de San Marcos. Fue sólo propuesto por Pedro IV en 1345. J. Jordán, Historia de la provincia de la Corona de Aragón de la sagrada Orden de los Ermitaños de N. G. P. S. Agustín, 1, Valencia 1704, PP. 210-211.
} 
distinguía por sus conocimientos de letras scientia litterarum ${ }^{40}$. Ese mismo año, le puso de relieve fray Alfonso Vargas de Toledo, que se graduó con él, en la Universidad de París y le cita varias veces en su comentario In primum sententiarum, donde le alaba y considera como "doctoris nostri"

El P. Antonio García y García fue el primero que dio a conocer Concordantiae decretorum cum Biblia" de Bernardo Oliver en España ${ }^{42}$. Él me facilitó el microfilme del Ms. 50 de la Biblioteca del Colegio de España en Bolonia, donde aparecía el tratado, cuya transcripción comencé y lo dejé aparcado, por diversas razones, teniendo que devolver el microfilme. Mejor suerte tuvieron los otros dos microfilmes, que me facilitó el mismo P. Antonio García y García, uno sobre fray Francisco de Castelló ${ }^{43}$ y otro sobre Martín de Córdoba ${ }^{44}$. Se llegó a pensar incluso en hacer la tesis doctoral en Derecho canónico sobre Bernardo Oliver; pero se abandonó y se cambió de tema, al estar comprometido con la historia de los agustinos en Venezuela y tener una petición especial del jesuita P. José del Rey Fajardo, que era entonces rector de la Universidad Católica del Táchira y quería saber cómo los agustinos habían evangelizado en los Andes venezolanos ${ }^{45}$.

La obra de Bernardo Oliver, Concordantiae decretorum cum Biblia, requería un estudio especial para cuando tuviese tiempo disponible, mientras el antiguo amigo y benemético historiador, P. Balbino Rano, realizaba un buen trabajo sobre este agustino "primer obispo agustino español" de tres diócesis distintas, y predicador de la curia pontificia de Aviñón, pero se equivocó, como Benigno Fernández, al considerarle "Bernardo de Oliver" debido a que aparece a veces su apellido en genitivo ${ }^{46}$.

En las crónicas y documentos del siglo XIV aparece siempre Bernardo $\mathrm{Oliver}^{47}$, como lo reconoce en parte el P. Balbino Rano, que afirma lo si-

\footnotetext{
${ }^{40}$ Archivo Vaticano, Reg. Vat. A63, Epist. 48, f. 62.

${ }^{41}$ A. VARgas de Toledo, In primum sententiarum, Venecia 1490, reimpresión 1952, cc. 10-11, 64-65, 148-150.

${ }^{42}$ A. GARCÍA y GarCíA, "La canonística ibérica medieval posterior al Decreto de Graciano", en Repertorio de Historia de las Ciencias Eclesiásticas en España, Salamanca 2 (1971) 187-188.

${ }^{43}$ F. CAMPO DEL Pozo, "Allegationes sobre la potestad eclesiástica. Opúsculo inédito de fray Francisco de Castelló”, en Estudio Agustiniano, 10 (1975) 455-489.

44 "Opúsculo sobre la potestad eclesiástica de Martín de Córdoba", en La Ciudad de Dios, 208 (1995) 661-698.

${ }^{45}$ F. Los Agustinos en la Evangelización de Venezuela, Caracas 1979.pp. 33-34 y 168-172, donde se menciona el Derecho Canónico medieval y el Agustinismo Político.

${ }^{46}$ B. FernándeZ, "D. Fr. Bernardo de Oliver”, en La Ciudad de Dios, 69 (1906) 112-123. El mismo autor pone Bernardo Oliver", en ibíd., pp. 206-211. Cf. F. CAMPO DEL Pozo, "P. Balbino Rano Gundín (1933-2005)", en Archivo Agustiniano, 9 (2008) 295-296, nota 46.

${ }^{47}$ Pedro iv, Crónica, "atribuida al secretario real Bernal Desclot hoy identificado con Bernat Escrivà”, ed. de J. Coroleu, lib. III, cap. 1, Barcelona 1885, p. 116.
} 
guiente: "Se le llama ordinariamente Bernardo Oliver y a veces de Oliver. En realidad su apellido en español debiera ser de Oliver, Olivarius. Sin embargo en documentos y escritos en catalán, él mismo afirma que se llama fratre Bernat Oliver" ${ }^{48}$. Se le conoció como Bernardo Oliver y así lo reconocen casi todos sus biógrafos ${ }^{49}$.

\subsection{Sus primeros años, estudios y cargos hasta llegar a ser obispo de Huesca}

Se consideraba que había nacido el año 1295 en Valencia y que sus padres eran nobles y le dieron oportunidad para adquirir una educación esmerada, como afirmó Jaime Jordán ${ }^{50}$. Según Manuel Villegas debió de nacer hacia 1280, porque según las Constituciones de 1290 se exigía tener 35 años para ir a un estudio superior, aunque se dispensaba a veces algunos años. ${ }^{51}$

Ya era un buen latinista cuando tomó el hábito agustiniano en el convento de Valencia de manos del venerable P. Francisco Salelles, antes de 1310. Por sus buenas dotes intelectuales, le destinaron los superiores a la Universidad de París para cursar Filosofía, Teología y Cánones. Se graduó en París de Bachiller con la lección sobre las Sentencias de Pedro Lombardo en 1315. Luego de Maestro en $1320^{52}$. En aquella época, en París predominaba la Teología, mientras que en Bolonia sobresalía más el Derecho. Siendo Bachiller escribió en Aviñón su tratado Contra caecitatem iudeorum, que no admitían a Cristo como Mesías basándose en textos del Antiguo Testamento ${ }^{53}$. Hay varios manuscritos, donde se afirma que habían pasado 1247 años desde el año 70 de la era cristiana, por lo que se puede precisar la fecha de su composición. No así el de Concordantiae decretorum cum Biblia "Concordancias de los Decretos con la Biblia", que es proba-

${ }^{48}$ B. RANO., "Fray Bernardo de Oliver, primer Obispo agustino español (Huesca, Barcelona, Tortosa). Predicador ante la Curia Pontificia de Aviñón”, en La Ciudad de Dios", 250 (1988) 392.

${ }^{49}$ A. LAmbert, "Bernard Oliver, evêque de Huesca, Barcelona et Tortosa", en Dictionnaire d Histoire et de Géographie Ecclésistique.” 7 París 1935, pp.756-759 y RuBIO, Fernando, "Bernardo Oliver", en Diccionario de Historia Eclesiástica de España, 3, Madrid 1973, p. 1805.

${ }^{50}$ J. JoRdAn, Historia de la provincia de la Corona de Aragón, pp. 209-212.

${ }^{51}$ I. Aramburo Cendoya, Las primitivas Constituciones de los Agustinos (Ratisbonenses de 1290), Valladolid 1966, pp. 110-111. M. Villegas, Fray Bernardo Oliver (1280?1348 Ms. p. 27.

${ }^{52}$ A. Zumkeller, "Die Augustierschule des Mitelalter”, en Analecta Augustiniana, 27 (1964) 174, donde aparece la lista de los graduados en la universidad de París en el siglo XIV.

${ }^{53}$ F. VendRell DE MiLAs, "La obra polémica de antijudaica de Fray Bernard Oliver", en Sefarat, 5 (1945) 303-3336; F. CANTERA Burgos, Edic. crítica y bibliografía de Contra caecitatem iudeorum, Madrid-Barcelona 1965. 
blemente posterior a su graduación como Maestro. El 10 de abril de 1318 se encontraba en el convento de Aviñón. Algunos afirman que después de su graduación de Doctor, regentó en París durante varios años una cátedra de Teología ${ }^{54}$. Pudo haber sido también antes de graduarse de Maestro.

De vuelta a España, hacia 1320, se encargó de la cátedra del Maestro de las Sentencias en la Universidad de Valencia, siendo el primer eslabón de una serie de profesores agustinos, "que sucesivamente la desempeñaron desde aquella época hasta los tiempos inmediatos a la exclaustración" 55 .

Ocupó puestos de relevancia como definidor y luego provincial. Según Jaime Jordán, fue dos veces prior provincial y, el 7 de octubre 1329, siendo provincial, se le comisionó para escribir 53 páginas para la provincia ${ }^{56}$. El historiador Lorenzo de Villanueva afirma que el 24 de marzo de 1327, el Maestro Fr. Bernardo Oliver, provincial de los agustinos, trató con el obispo de Lérida, Raimundo, que murió el 12 de agosto de ese año, y "logró la fundación del convento de su Orden en la iglesia de Santa María de Orta, propia de una cofradía, que entonces pasó a San Salvador" ${ }^{57}$.

Consta que, el 17 de junio de 1329, figura entre los definidores al Capítulo General, "Frater Bernardus de Cathelonia bachelarius, deffinitor provincie Arragonie (sic)". En dos manuscritos de su obra Contra cecitatem iudeorum, aparece "Bernardus Oliverii de Cathalonia" 58 . Hay variantes al escribir Cathalonia y Oliverii.

Tenía tan buenas dotes de gobierno, ciencia y predicación que su fama llegó a la Corte del rey Pedro IV de Aragón, nombrándole su predicador y consejero. En una de las comisiones confiadas por el dicho rey a fray Bernardo. Oliver, se hizo el 30.6.1332 como embajador ante la curia pontificia de Avignon, relacionándose con Juan XXII. Entonces era ya Maestro en Teología, como consta en una carta de ese año sobre los asuntos que se estaban tramitando. Allí predicó ante el papa y los cardenales en $1334^{59}$.

\footnotetext{
${ }^{54}$ G. DE SAnTiago Vela, Ensayo de una biblioteca ibero-americana de la Orden de San Agustín, 6, Madrid 1922, pp. 74-88, donde aparece su biografía y bibliografía hasta entonces conocida. Es abundante la bibliografía posterior, al publicarse algunos de sus escritos y por su actitud anti-judaica, que ha dado origen a no pocas polémicas.

${ }^{55}$ V. Villalonga, "Crónica”, en Revista Agustiniana, 11 (1886) 82-83. En el claustro universitario de Valencia existe un cuatro de Fray Bernardo Oliver.

${ }^{56}$ J. JORDAN, Historia de la provincia, pp. 157 y 210.

${ }^{57}$ J. LoRenzo Villanueva, Joaquín, Viaje literario a las Iglesias de España, XVII, Madrid 1851, pp. 76-7.

${ }^{58}$ F. CANTERA Burgos, El tratado "Contra caecitatem iudeorum”, edic. crítica y bibliografía, Madrid - Barcelona, 1965, p. 67. B. RANO, "Fray Bernardo de Oliver”, p. 394.

${ }_{59}$ H. Finke, "Nachträge und Ergänzungen zu den Acta Aragonensia", en Spanische Forschungen der Görresgesellschaft, serie I, 4 (1933), 511.
} 
A instancias del mismo rey, el papa Benedicto XII le nombró obispo de Huesca el 1 de octubre de 1337, al haber renunciado Geraldo de Rochabertino. Se rumoreó que había sido propuesto por el cabildo de Huesca. Para entonces ya tenía compuesta la obra de Concordantie decretorum cum Biblia, donde aparece como obispo de Huesca ${ }^{60}$. Hay bastante documentación sobre su actuación como obispo de Huesca. Esto está publicado en su mayor parte con la documentación pertinente.

Se encontraba en Aviñón cuando el papa Clemente VI le promovió el 12 de enero de 1345 para obispo de Barcelona ${ }^{61}$. Finalmente fue trasladado a Tortosa por bula del 26 de junio de $1346^{62}$. Tomó posesión el 12 de agosto. En 1348 realizó su última misión política. Murió en Tortosa el 14 de julio de $1348^{63}$.

\section{2 El códice de Bolonia y las "Concordantiae decretorum cum Biblia"}

Este códice 50 de la Biblioteca del Real Colegio de España en Bolonia, lo dio a conocer en España, el P. Antonio García y García, que me facilitó el microfilme en 1971, como se ha observado anteriormente. Ha sido estudiado también por F. Stegmüller y su continuador Klaus Reinhart ${ }^{64}$ y por el mismo P. Antonio García y García, como colaborador de una obra sobre los códices del Colegio de España en Bolonia, donde aparece el comienzo y el fin de la obra de Bernardo Oliver ${ }^{65}$.

En el mismo códice 50, hay otros tres opúsculos, uno sobre el mismo tema y dos sobre la predicación, como luego veremos. Se trata de un códice bien conservado y encuadernado del siglo XV con cubierta de cartulina, 285 x 215, mm., 145 y 2 col. El último folio se lee mal y no aparece en el mi-

${ }^{60}$ Biblioteca del Real Colegio de España en Bolonia, códice 50, ff. 75r. Se agradece al P. Antonio García y a E. Coser su colaboración para conocer y tener copia del manuscrito, cuyo título es: "Concordantie decretorum cum Biblia composite a magistro Bernardo Oliveri, episcopo Oscense, qui posterius (prius según A. García) fuit episcopus Dertusensis”. Ya en el f. II, preliminar, se observa que en vez de posterius o postea (forte legendum prius). Esto se constata por su vida. Es fácil confundir la abreviatura prius con posterius. Las erratas siempre son posibles.

${ }^{61}$ Archivo Vaticano, Reg. Vat. 163, f. 61v, Epist. 47.

${ }^{62}$ Ibíd., 177, Epist. 44v-45r. Tomó posesión el 12 de agosto.

${ }^{63}$ B. RANo, Balbino, "Fray Bernardo de Oliver", pp. 402-411.

${ }^{64}$ F. STEGMÜLleR, Repertorium biblicum Medii Aevi, Suplementum, 8, C.S.I.C., Madrid 1976, n. 1732, p. 353. K. ReInHART y S. Оtero-Otero, Biblioteca bíblica ibérica-medieval, C.S.I.C., Madrid 1986, pp. 124-127.

${ }^{65}$ D. Mafrey, F. Cortese, y A. García, etc. I, Codici del Collegio di Spagna di Bolonia di Spagna di Bolonia, Giufrè, Milano 1992, p. 60. Comienzo de Concordancias de Bernardo Oliver: "Volenti procedere utiliter in hoc opere tria sunt primitus attendenda", etc. Y termina: "Qui audit. Dicta Veni XXXVI, disc. Ecce quod sacrarum. Deo gratias". 
crofilme. Entre los folios I y II ha y dos folios rotos. La letra es bastarda, derecha y reposada; letras iniciales afiligranadas en rojo y azul. La paginación antigua en cifras arábigas es posterior al texto. Se trata de 12 fascículos con notas al final. Los dos folios extremos y los dos entrantes son de pergamino, mientras que son de papel los restantes. En el f. Ir. Hay una anotación del siglo XVI: "Memoriale Bibliae ac Decreti"

Al hacer la trascripción del texto se ha notado que, al encuadernar el fascículo de Bernardo Oliver, se alteraron algunos folios, así, lo que es fol.79, debería ser f.78. Se comprobó esto por las citas de la Biblia, ya que en el f.79 se refieren al final del Génesis, y el f.78 al comienzo del Éxodo. Al hacer la trascripción se presentaron también algunos problemas paleográficos, que se fueron resolviendo, aunque en otros casos quedaban dudas, al no tener otro texto para hacer una edición crítica y ver las variantes. En algunos casos se dudaba si era folio recto o vuelta. Esto se clarificó al obtener un nuevo microfilme y ver el texto en Bolonia. El Memorial del Decreto con la Biblia de Juan de Juanes, que está antes, es más amplio que las Concordancias de Bernardo Oliver, con algunas afinidades y diferencias, incluso coincidencias lógicas por los textos comunes citados de la Biblia y del Decreto. Aunque la obra de Juan de Juanes va antes en el códice 50, es posterior en el tiempo como luego veremos. En el mismo códice hay dos obras más: Libro del arte de predicar de Jacobo de Fusignano ${ }^{67}$, dominico, y otra Tratado de la predicación, de Luis de Rocha ${ }^{68}$.

Bernardo Oliver fue ante todo un decretista o comentarista del Decreto de Graciano, cuya obra se titulaba Concordia discordantium canonum, que apareció en 1142 en forma de Excepta y luego en 1148, como Concordia, y, finalmente, en 1150 , como Decretum ${ }^{69}$. Se trata de una colección satisfactoria, que recapitulaba el primer milenio y se llegó a imponer en el Derecho Canónico, como el Libro de las sentencias de Pedro Lombardo en la Teología. Fue también "decretalista" porque el título es "Concordancias de los Decretos con la Biblia". Cita algunos textos del Corpus Iuris Canonici, pero casi todo es del Decreto de Graciano

En la obra de Bernardo Oliver se dan las citas o textos, que el Decreto de Graciano contiene de la Biblia como autoridades, desde el Génesis hasta el Apocalipsis. Estas Concordancias dan apoyatura al Decreto de Graciano,

${ }^{66}$ Ibíd.,pp. 60- 61, donde se da una descripción más completa y la bibliografía existente.

${ }^{67}$ J. DE FUSIGNANO, Libellus artis praedicatoriae, ff. 121-134.

${ }^{68}$ L. DE Rocha, Tractatus de praedicationae, ff. 135-144.

${ }^{69}$ J. M. VIEJo-XIMÉnEZ, "Gratianus Magister y Guarnerius Teutonicus", en Jus Canonicum, 41 (2001) 50. Hay muy buenos estudios. Uno de los mejores es el de A. WinRoth, Marking of Gratianus Decretum, Universidad de Cambridge 2005. 
que es una colección privada y se convierte en oficial dentro del Corpus Iuris Canonici, desde el siglo XII hasta el Código de Derecho Canónico de 1917. Sigue siendo una fuente para conocer la canonística del primer milenio con mucha influencia hasta el siglo XX, y aún hoy es obra de obligada consulta.

Se comenzaron a realizar glosas ordinarias al Decreto a finales del siglo XII, en las que se hace ver también la vinculación entre las Escuelas de Teología y de Derecho Canónico, algo que venía haciéndose desde el comienzo del mismo siglo con Anselmo de Laón y Rolando Bandinelli que llegó a ser papa con el nombre de Alejandro III. Se menciona a Graciano junto con Irnerio por el preboste del monasterio premostratense de Ursbeg de Suabia, Burcardo de Bibnerach ${ }^{70}$. Hay que tener en cuenta a Juan Teutónico, el que hizo la glosa ordinaria al Decreto y autor de la IV Compilatio en 1217, aceptada en Bolonia en 1220. Siendo privada, contiene los cánones del Concilio IV de Letrán de 1215 y diversas decretales de Inocencio III. El Decreto de Graciano seguía siendo una obra de comentarios canónicos y bíblicos, como eran los IV Libros de las Sentencias de Pedro Lombardo para los teólogos.

El hecho de que el texto de la obra de Bernardo Oliver se encuentre en Bolonia es porque en esa universidad se le tuvo en cuenta, especialmente por los canonistas hispanos del Real Colegio fundado por el cardenal Albornoz. Cuando se prohibió en la Universidad de París estudiar allí Derecho Romano, se fueron a Bolonia, donde se explicaba esta materia. Llevaban también manuscritos de París a Bolonia y viceversa.

\subsection{Valor de esta obra y su relación con la obra del abad Juan de Juanes}

El valor de las Concordancias de los Decretos con la Biblia de Bernardo Oliver es muy grande porque refleja la apoyatura del Derecho canónico en la Palabra de Dios, como autoridad suprema. Se hace una Teología del Derecho, aceptando el texto de san Pablo que "toda potestad viene de Dios" "11. Los textos de la Biblia son autoridades con valor especial, por tratarse de textos escritos por inspiración divina.

El texto del Memoriale Decreti de Juan de Juanes, Abad Nivicellense, (Niveles, Bélgica) comienza con un pequeño preámbulo, que se recoge en la Rúbrica: "Comienza el Memorial del Decreto, compuesto por fray Jo-

${ }^{70}$ J. M. VIEJO-XIMÉNEZ, "Gratianus Magister y Guarnerius Teotonicus”, pp. 54-56, donde se hace ver también que hay unas 200 citas del Corpus Iuris Civilis de Justiniano.

${ }^{71}$ SAn PABLO, Epístola a los Romanos, 12, 1: "Non est potestas nisi a Deo". 
hannes Johannis abbate Iuncellum, doctor de los decretos, que contiene [mejor dicho iba a contener] cinco partes [y de hecho, sólo contiene la primera]: "En primer lugar, las autoridades de la Biblia, [que aparecen en el Decreto de Graciano] exponiéndolas según el orden de libros y capítulos de la Biblia; en el segundo lugar, los dichos o frases de poetas, especialmente los santos; en tercer lugar algunas autoridades textuales más notables del Decreto redactadas por orden alfabético; en cuarto lugar, la exposición de las dicciones, y en quinto lugar las glosas por el orden antedicho"72. Del proyecto de cinco partes, sólo aparece la primera en el manuscrito, cuyo texto comienza así: "En el principio creó Dios el cielo y la tierra", y sigue: "hágase el firmamento en medio de la aguas xxiii, q. v. Quid ergo in principio" etc. ${ }^{73}$ Juan de Juanes es posterior a Bernardo Oliver, que pudo servirle de fuente, ya que consta que éste "floreció por el año de 1460"

Fray Bernardo Oliver comienza la exposición afirmando: "En el principio creó Dios el cielo y la tierra, y luego dijo también Dios: hágase el firmamento." De estos textos consta que Moisés narra que en primer lugar se hizo el cielo y después el firmamento como se dice en De poen. d. II, c. 44 quod ergo reprobi ${ }^{75}$. Aquí ya se ve cómo comentando el mismo texto del Génesis lo hacen de distinta manera y con diferente apoyatura en el Decreto. Se han podido conocer y es posible que existan otras fuentes comunes. Al dar apoyatura bíblica a los textos del Decreto, se da una fundamentación teológica, como se ha observado. Se va haciendo desde el Génesis hasta el Apocalipsis, pasando con los distintos libros que se citan siguiendo el orden de la misma Biblia. Los textos no son siempre de la Vulgata de san Jerónimo y hay variantes. Sobre esto hay que hacer un estudio complementario.

\section{Francisco Castelló y sus “Allegationes" sobre la potestad eclesiástica”}

Fray Francisco Castelló forma parte de los juristas y teólogos valencianos. Fue maestro en Sagrada Teología y catedrático de Sagrada Escri-

${ }^{72}$ El libro de Juan de Juanes comprende los ff. 1-74. Esta obra es casi el doble que la de Bernardo Oliver. Aunque va antes en el manuscrito, es posterior, como se ha observado.

${ }^{73}$ Ibíd., f. $1 \mathrm{r}$

${ }^{74}$ F. STEGMÜLler, Repertorium bíblicum, (Continuación), IX, Madrid 1977, n. 4834, donde se corrige un error o errata, ya que se suponía del año 1070 y es 1460, como ha informado el antiguo y buen amigo Klaus Reinhardt, en carta del 22 de enero de 2001, al hacerle una consulta, a la que contestó al día siguiente por correo electrónico. Nicolás Reinhardt es discípulo predilecto de Federico Stegmüller y continuador en Tréveris, donde ha estado al frente de la Facultad de Teología.

${ }^{75}$ B. Oliver, Concordantie, f. 75 r. 
tura en la Universidad de Valencia a finales del siglo XIV y probablemente allí expuso las "Alegaciones", aunque fueron a parar a la Universidad de Salamanca, donde las halló el P. Antonio García y García, que me facilitó la fotocopia en 1970, para hacer la trascripción ${ }^{76}$.

Nació en Valencia, donde tomó el hábito agustiniano en el convento de dicha ciudad. Son pocos los datos que se tienen sobre él. Consta que el año 1393 se encontraba en Castellón, recogiendo fondos para la reconstrucción del convento agustiniano de aquella villa, por lo que algunos creen que era de allí, lo que daría origen a su apellido. El 4 de junio de 1399 era provincial y profesor de Sagrada Escritura, según consta en el registro del Archivo de la Curia de Tortosa, copiado por el P. Tomás de Herrera: "El 4 de junio de 1399, Guillermo de Raimundo dio licencias para predicar y para confesar al varón honorable y religioso, fray Francisco Castelló, provincial, profesor en sagrada página" 77 .

Fr. Francisco Castelló es omitido por el P. Gregorio de Santiago Vela. Aparecen Francisco de Castillejo y N. de Castillejo, que son de Córdoba y posteriores, con alguna confusión de obras entre ambos ${ }^{78}$. El texto de las Allegationes sobre la potestad eclesiástica de fray Francisco Castelló debió de ser escrito en Valencia, en cuya Universidad era profesor y luego fue a parar a Salamanca, ya que en aquella época iban las copias manuscritas de una Universidad a otra por la intercomunicación existente.

Al hacer un primer estudio sobre la vida y obra de Fray Francisco Castelló, se precisó su nombre por Jordán de Sajonia y se comprendió su pensamiento dentro de la ideología canónica, jurídica, política, teológica y eclesiástica, que fue denominada con acierto por Henry Xavier Arquillière, "Agustinismo Político" por inspirarse en textos de san Agustín y sus comentaristas ${ }^{79}$. Esta doctrina, con la de la Cristiandad medieval, me era familiar por un trabajo anterior sobre san Agustín ${ }^{80}$.

Se hizo la edición crítica de este opúsculo con una introducción sobre su doctrina, que sigue a los juristas agustinos italianos y de la Escolástica en general, con los condicionamientos sociológicos, culturales y políticos del siglo XIV en el reino de Valencia como vamos a ver ${ }^{81}$. Del trabajo publi-

${ }^{76}$ F. CASTELLO, "Allegationes honorabilis fratris Francisci Castilionis ordinis fratrum heremitaum beati Augustini, in Sagrada Teología Magistri”, Biblioteca Universitaria, Salamanca, Ms. 1861, ff. 45 v-55r. Fue necesario ver el texto original y todo el códice.

${ }^{77}$ T. DE Herrera, Alpabetum Augustinianum, 1; Madrid 1644, p. 164.

${ }^{78}$ G. De Santiago Vela, Ensayo, I, p. 652.

${ }^{79}$ H. X. Arquillière, L'Agustinisme Politique, Paris 1855, 206 pp.

${ }^{80}$ F. CAMPo Del Pozo, Filosofía del Derecho según san Agustín, pp. 128-138.

${ }^{81}$ F. CAMPO DEL POZO, "Allegationes" sobre la potestad eclesiástica". Opúsculo inédito de fray Francisco Castelló, en Estudio Agustiniano, 10 (1975) 455-489. 
cado se hace aquí un extracto, observando que ha sido poco conocido y se sigue omitiendo en obras recientes como en Los agustinos ermitaños en España hasta el siglo XIX, por el P. Basilio Estrada Robles en 1988. Se dieron cuenta de su valor autores alemanes, como A. Zumkeller, y españoles, como el P. David Gutiérrez ${ }^{82}$.

\section{1. Motivos de las "Allegationes" en la ciudad de Valencia}

El motivo principal de este opúsculo fue un enojoso pleito entre la sociedad civil y la eclesiástica a principios del siglo XV en Valencia, al intervenir la justicia y quitar las armas a unos clérigos, que eran simplemente tonsurados y además estaban casados. Debido a eso, las "Allegationes" debieron ser escritas entre 1419 y 1427. En 1419 tuvo lugar la intromisión de los jueces seculares en la jurisdicción eclesiástica, y en 1427 muere el obispo Hugo de Lipia e Ibagué. Esta causa con las "Allegationes" había sido llevada a Roma ${ }^{83}$.

El caso fue sometido a una comisión de expertos o peritos, entre los que figuran Arnoldo de Conchis (Dr. en leyes); Juan Moya, (Lic. en leyes); Bernard, buen hombre (Dr. en cánones); Juan Lobera (Dr. en leyes); Jenaro Rabaca (Dr. en leyes); Miguel de San Juan (Dr. en ambos Derechos); Juan Mercader ( Dr. en leyes); Bernardo Flamerich (Dr. en leyes); Pedro Esculano (Dr. profesor en leyes); Domingo Manso (profesor de leyes); más los teólogos Francisco Eiximensis O.F.M.; Francisco Castillionis y Juan Montesono O.P. Francisco Castelló o de Castelló, agustino, fue consultado como teólogo y sus "Allegationes" aparecen en el séptimo lugar. Contestó a la consulta que hizo el obispo, observando que algunos habían intervenido como árbitros: Jenaro Rabaca y Juan Lobera ${ }^{84}$.

Estas Alegaciones corresponden por su estructura al género literario jurídico de los "consilia" calificado así al final de algunos informes, porque ellos era lo único que podían hacer para refutar la doctrina de Giordano de Osnabrück con su tratado de Prerrogativa imperii, traducido al catalánvalenciano, junto con las ideas laicistas de Nogaret y otros de la corte del rey

${ }^{82}$ D. GutiÉrReZ, Los Agustinos en la edad media l357-1517, 2, Roma 1977, p. 279.

${ }^{83}$ E. Olmos y Canalda, Inventario de los pergaminos del Archivo Catedral de Valencia, Valencia 1961, n. 4.834; "Letras compulsatorias por la Curia Romana en la causa del Obispo de Valencia en la Curia Real, 3 de nov. 1419" (Pergamino 6.719); n. 4.3836: "Comisión del Obispo de Valencia para absolver a los jueces seculares por intromisión en la jurisdicción eclesiástica, 19 de nov. 1419 (pergamino 2.676).

${ }^{84}$ F. CASTElló, “Allegationes”, Biblioteca Universidad de Salamanca, Ms. 1881, ff. $27-28$. 
Felipe el Hermoso de Francia. Se cuestionaba también "si estaba permitido al obispo dar licencia a los clérigos para portar armas con causa justa" ${ }^{155}$.

En el mismo manuscrito hay un libro de Pedro Bertrando, doctor en ambos derechos, profesor, obispo y entonces cardenal que había sido traducido del francés al Latín, sobre algunas cuestiones habidas entre el rey de Francia y los prelados (1.9. 1339) ${ }^{86}$. A estos autores y tratados acude Francisco Castelló para dar respuesta o solución al problema planteado, refutando las doctrinas heterodoxas ${ }^{87}$.

Francisco Castelló da su opinión sobre el litigio, con la particularidad de no descender a detalles del caso propuesto, sino que se limita a exponer los principios generales, conforme a los cuales debía solucionarse el problema existente entre el poder civil y eclesiástico. Pone de relieve los derechos y deberes de los bautizados, acudiendo a la tradición bíblico-patrística y a los teóricos del Derecho civil y eclesiástico de finales del siglo XIII y comienzos del siglo XIV. Se pone de parte de los defensores de la superioridad del "Sacerdocio" sobre el "Reino", admitiendo la separación de poderes y reafirmando la potestad directa a veces y también la indirecta de la Iglesia en lo temporal relacionado con lo espiritual. Como se ha observado anteriormente, reconoce el hecho de que los clérigos estaban armados y la intervención de la autoridad civil, que debe contar con la autoridad eclesiástica, de acuerdo con los principios de mutua cooperación y la superioridad del poder eclesiástico sobre el civil.

\section{2. Doctrina teocrática defendida por fray Francisco Castelló}

Defiende la doctrina teocrática del pontificado, partiendo del principio de que Cristo fue ungido por Dios, según su humanidad, como Rey y Sacerdote de todo el orbe, lo cual prueba con textos de la Biblia, especialmente de san Pablo. Ahora bien, Cristo dio a san Pedro, como Vicario suyo y a sus sucesores, ambas potestades; luego el papa tiene plena potestad espiritual y también temporal: "Cum igitur papa habet plenam potestatem spiritualibus, sequitur quod habet plenariam potestatem in temporalibus" 88 .

Hay muchas citas del Decreto y algunas de las Decretales, especialmente de la bula Unam Sanctam, según la cual, el papa podía juzgar sobre

${ }^{85}$ Ibíd., ff. 27 y 104-123.

${ }^{86}$ Ibíd., ff. 104-123.

${ }^{87}$ Ibíd., f. 65. El cardenal Pedro Bertrando fue defensor de la teocracia: "temporalia ordinatur ad spiritualia tanquam ad finem".

${ }^{88}$ F. CASTELLÓ, Allegationes, f. 46. 
las cosas temporales, si fuese necesario, porque el papa es rey de reyes" 89 . Considera herética la opinión de aquellos que niegan al papa la potestad de juzgar en lo temporal. Refuta especialmente el libelo que afirma "que toda alma es súbdita de su rey en lo temporal y en aquellos que del rey reciben beneficios temporales, como los obispos en lo espiritual"

Conviene tener en cuenta que Francisco Castelló no defendió que la potestad de juzgar de los obispos en lo temporal sea siempre inmediata y directa. Es más, observó que, aunque Cristo fue rey, no quiso entrometerse en juicios seculares. Esto debían de tenerlo en cuenta los prelados, aunque algunos opinaban lo contrario ${ }^{91}$. Llega a defender con argumentos sólidos que es más oportuna y conveniente la potestad mediata o indirecta en lo temporal, procurando tener la colaboración del poder secular con el eclesiástico. Sigue la doctrina del llamado "Agustinismo Político" apoyado en textos de san Agustín y sus comentaristas, reconociendo que en su tiempo la Iglesia estaba estructurada de un modo diferente a los primeros siglos, y que la misma Iglesia trataba de justificar sus posesiones y dominios con leyes y decretos, que le convenían y "si promulgaron tales decretos, esto lo hicieron movidos por el Espíritu Santo, que rige a la Iglesia espiritualmente en las cosas morales" $"$. Esto da origen al principio de que la Iglesia puede valorar y dar su opinión sobre los actos y acontecimientos del poder civil.

Hay que valorar y ver este opúsculo dentro de su tiempo, en el que recomienda a los obispos que no se metan demasiado en materia temporal, aunque, como la Iglesia, tienen autonomía para juzgar en lo espiritual y lo material conexo con lo espiritual. Con razón ha afirmado Francisco Javier Conde que los "teólogos y juristas medievales no hicieron otra cosa que llevar a las últimas consecuencias la inspiración agustiniana" ${ }^{93}$. Con este opúsculo de Francisco Castelló se clarifica un poco la situación de la Iglesia en España en los siglos XIV y XV, cuando hacían crisis algunas instituciones con la agonía de viejas estructuras de España y Europa, en las que predominaba la autoridad de la Iglesia, que se enfrentaba a los nuevos Estados con más fuerza y autonomía.

Ha habido otros canonistas en la Universidad de Valencia como Juan Bautista Ruiz, que en 1370 era doctor en Sagrados Cánones y Teología;

${ }^{89}$ Ibíd., f. 47.

${ }^{90}$ Ibíd., f. 48v. Se dan textos en catalán valenciano. Cf. F. CAMPo DEL Pozo, “Allegationes sobre la potestad eclesiástica", p. 473, donde se menciona al famoso Arnoldo de Vilanova, que es considerado por algunos como de su familia; pero no consta.

${ }^{91}$ F. CASTElló, Allegationes , f. $53 \mathrm{r}$

92 Ibíd., f. 53v.

${ }^{93}$ F. J. Fernández Conde, "El Agustinismo Político y su importancia en la evolución histórica del Medievo”, en Burgense, 13 (1972) 458. 
Pedro Fabra, profesor de cátedra de cánones hasta 1406; Gabriel Romeo por los años de 1440, y Jaime Pérez de Valencia en 1459; pero no consta que dejasen escritos en Derecho canónico.

\section{Fray Juan de Alarcón, su "Libro del Regimiento de los Señores del Li- cenciado"}

Fray Juan de Alarcón (1390-1451) nació en Alarcón (Cuenca) y llegó a ocupar un lugar relevante en los temas canónico-morales. Se graduó en la Universidad de Florencia, a donde fue promovido por el Capítulo General de 1419 para la lectura de Biblia en el convento de esa ciudad, autorizándole para que pudiese incorporarse a aquella Universidad y proseguir su lectura como lo atestigua el P. Gregorio de Santiago Vela, que clarificó ser el autor del Libro del Regimiento de los Señores del Licenciado de San Agustín, porque aparecía como el Licenciado en varias actas ${ }^{94}$.

Ya el P. Tomás de Herrera observó que Juan de Alarcón se licenció en Teología en la Universidad de Florencia y no continuó allí sus estudios para obtener otros grados superiores, movido por el ejemplo y austeridad que veía en sus hermanos de Italia, acariciando la idea de introducir en España el mismo régimen en los conventos de la Orden. Aprobó su determinación el P. General, Agustín de Roma, el 15.4.1431, para fundar el convento de Villanubla (Valladolid) denominado el de los Santos, aunque allí fueron algunos religiosos presos para hacer penitencia. En otro decreto del $17 \mathrm{del}$ mismo mes se le nombró Presidente y Vicario General del capítulo que se iba a celebrar en Dueñas el año $1432^{95}$.

Otro gran historiador de la Orden, el P. Jerónimo Román, en sus Centurias afirmó que "el venerable [fray Juan de Alarcón] fue gran teólogo y muy privado del Rey Don Juan Segundo", a cuya protección y la del famoso Don Álvaro de Luna, que era el que gobernaba entonces Castilla, se debió el que tomase auge la Congregación de la Observancia, de la que fue nombrado Vicario General en 1438. Los problemas del convento de Salamanca se solucionaban en la corte, como algunos problemas de la corte se solucionaban en los conventos ${ }^{96}$. La Congregación de la Observancia llegó a estar formada por los conventos de Arenas de San Pedro (Ávila), Dueñas

\footnotetext{
${ }^{94}$ G. DE Santiago Vela, Ensayo, I, pp. 71-72

${ }^{95}$ Ibíd., p. 71, donde cita a T. DE HERRERA, Historia del convento San Agustín de Salamanca, Madrid 1652, pp. 29-30

96 J. Román, Chrónica de Orden, f. 82.
} 
y Valladolid. De las monjas abrazaron la observancia las de Madrigal. El libro fue escrito, en parte, para agradecer la ayuda prestada a los agustinos por el Don Álvaro de Luna, al que deseaba orientar conforme a la doctrina de Egidio Romano y sus seguidores.

\subsection{El "Libro del Regimiento de los Señores" y su contenido}

Aunque Juan de Alarcón escribió también libros sobre los novicios y los votos, con títulos semejantes a los de otros autores, como de Institutione votorum de Hugo de San Víctor, su obra principal es el Libro del Regimiento de los Señores, cuyo manuscrito se conserva en la Biblioteca Nacional ${ }^{97}$. Se sabe que formó parte de la Biblioteca del Conde de Haro, fundada en 1455. Se hizo una descripción de este libro por Antonio Paz y Meliá en 1789 sin decir nada de este Licenciado agustino, cuyo nombre podía ser el de Martín de Córdoba, como supuso el P. Conrado Muiños por una poesía que está dedicada también al condestable, relacionándola con el Compendio de la Fortuna ${ }^{98}$, cuando no tiene nada que ver, porque se trata de algo bastante distinto. Fue escrito unos años antes de la muerte de Juan de Alarcón en 1451. Dos años después, el Condestable Don Álvaro de Luna fue decapitado en el cadalso de la plaza Mayor de Valladolid el 2.6.1453. Este libro tiene su valor lingüístico; pero mucho mayor jurídico-canónico y moral, porque su orientación es más bien moralizadora. Se sirvió de la Biblia, san Agustín y otros Santos Padres, con aditamentos de Egidio Romano, santo Tomás de Aquino y sobre todo de la Escuela Agustiniana, como se dice al principio: "Aquí comienza un libro compuesto de muchas autoridades de la Sagrada Escritura e de razones naturales e dichos de los santos doctores de la Santa Iglesia,"etc.

El primero que publicó este libro fue el P. Bonifacio Díez Fernández, haciendo un ensayo bastante bueno ${ }^{99}$. Lo reeditó con un estudio mejor el P.

${ }^{97}$ Biblioteca Nacional de Madrid, Ms. Bb. 9477, con letra del siglo XV, en papel 240 x 132 mm. Escritura, 150 x 96, Holandesa, $88 \mathrm{ff}$. Hay una traducción catalana, L[ibre] dels senyorst. Cat[alán). Perteneció al rey D. Martín II de Aragón. R. BEER, Handschristenschätze spaniens, p. 93.

${ }^{98}$ C. MuiÑos, "Discurso sobre la influencia de los Agustinos en la poesía castellana" en La Ciudad de Dios, 17(1888)177-179. Hay una poesía en sintonía con los versos de Jorge Manrique al final, en los dos últimos folios del Libro del Regimiento de los Señores, que comenta C. Muiños.

${ }^{99}$ B. Díez Fernández [DIFERNAN], "Libro del Regimiento de los Señores” en Anuario Escurialense, 2 (1961) 659-776. 
Fernando Rubio, haciendo constar que había seguido a Egidio Romano ${ }^{100}$. El Licenciado Agustino, Juan de Alarcón, nos dice en la Dedicatoria o introducción sobre su contenido, que lo divide en 6 partes: "En la primera, tratando cómo Dios gobierna e rige el mundo e tiene cura general de todas las cosas, e singular de cada una, según que a cada uno pertenece. En la segunda, cómo Dios ensalza a los que quiere, dándoles riquezas, gracias de Señores, esfuerzo, juicio e paciencia, perseverancia e denuedo, sin las cuales virtudes e otras semejantes, non cabría en ellos el bien temporal, y largamente les podría durar. La tercera, cómo los que así ensalza, se deben haber con Dios e deben con sus prójimos usar. En la cuarta, cómo muchos, de las honras e riquezas con que Dios les consoló, tomaron e toman ocasión de pecar. En la quinta, cómo Dios los soporta, e a las veces Dios les revoca e torna a sí despertando. La sexta, cómo arrepentidos e convertidos, deben a Dios buscar e a él servir e complacer, e cómo se deben con sus prójimos haber"101.

\subsection{Ideas claves de esta obra, su importancia y algunos juicios sobre ella}

Hay dos ideas fundamentales en este tratado: $1^{\text {a }}$ Que Dios rige el mundo y se sirve de los señores para realizar la justicia. $2^{\text {a }}$ Que Dios da a los pueblos los gobernantes que se merecen. Tiene un sentido providencialista y refleja en todo el libro una teoría política-democrática en función del bien común y de la justicia. Aunque cita muchas veces temas eclesiásticos, no se presenta el problema de las relaciones entre la Iglesia y el Estado, sino entre el gobernante y Dios. Los señores deben cumplir con sus deberes frente a los súbditos y la iglesia, teniendo en cuenta a los súbditos que también tienen sus derechos y deberes. Los Señores deben rendir cuentas a Dios y a sus súbditos.

En aquella época de grandes rivalidades, como admirador del Condestable Don Álvaro de Luna, le da consejos que aún hoy resultan impactantes. Sigue la doctrina de Egidio Romano, adelantándose a los acontecimientos. Según su doctrina, si hubiese sido procesado con un juicio justo, el condestable habría sido absuelto y digno de galardón o premio hu-

${ }^{100}$ F. Rubio, "Libro del Regimiento de los Señores" en Prosistas castellanos del siglo $X V, 7$ de la Biblioteca de Autores Españoles, 171, Madrid 1964, pp. 156-216; "De regimine principum de Egidio Romano en la literatura castellana de la Edad Media, Siglo XV”, en La Ciudad de Dios, 174 (1961) 652-654, donde hace ver la influencia de la obra de Egidio Romano en la de Juan de Alarcón.

${ }^{101}$ J. De Alarcón, “El Libro del Regimiento de los Señores”, ed. de Bonifacio Dífernan, 675-676. 
mano. No existía un derecho procesal con separación de poderes. El libro es un elogio y guía a Don Álvaro de Luna y para los que lo leyeren, como afirma en la dedicatoria: "A gloria e servicio del alto Dios que de los hombres virtuosos se sirve e contenta, e a provecho e consolación de los que este libro leerán, en especial de vos, señor Condestable, habiendo sentido en vos juicio, fondo de discreción, prudencia e fortaleza e otras virtudes...yo un indigno fraile de la orden de san Agustín, o quizá, me hizo Dios acordar e proponer en un libro e tratado para vos principalmente, donde para otros, trabajase de componer." etc. Esto está en la $5^{\text {a }}$ hoja del manuscrito. Sigue el Libro del Regimiento de los Señores, con una poesía en los dos folios finales, que tiene importancia también para ver la evolución del castellano, como se ha observado anteriormente.

Sorprende la crítica que le hace José Luis Villacañas Berlanga un tanto negativa, al valorar la obra con una óptica postmoderna y hasta kantiana. Tiene observaciones interesantes, como la de reconocer que la obra estaba integrada en el tiempo del Condestable Álvaro de Luna, al "que Dios ha prosperado y engrandecido mucho". Afirma que se estaba dando un proceso de "señorización, que sufrió la sociedad castellana bajo el reinado de Juan II". Lo que Egidio Romano aplicaba a los príncipes, que mandaban con autoridad divina, "se extiende a los señores". Todos ellos estaban sometidos "a los fines superiores de la Religión y de los valores cristianos". Se amplía esto a los señores jurisdiccionales, que en el fondo tenían los mismos poderes. En su opinión también "se les imponen ahora obligaciones ancestrales". Es cierto que, según Juan de Alarcón, existe un "gobierno divino del mundo, como arquetipo del gobierno de los señores mundanos, dentro de los cuales el rey es uno más". Hay que ver esto desde una Filosofía y Teología de la Historia, como lo hizo san Agustín en La Ciudad de Dios, no desde una óptica Kantiana al afirmar finalmente: "Aquí una vez más, Kant pudo decir con razón haciéndose cargo de las dificultades evolutivas de España, que la nuestra era tierra donde mandaban los antepasados" 102 .

Aunque soy germanófilo y en Colonia completé mi tesis doctoral, la filosofía kantiana siempre me resultó nebulosa, como el medio ambiente alemán, porque Kant no tenía la luz solar de Castilla para ver bien los pueblos y las tierras de España, donde canonistas y juristas agustinos han buscado la empatía en pro de los derechos humanos y la democracia, incluso

102 J. L. Villacañas Berlanga, "Reseña al Libro del Regimiento de los Señores. Fray Juan de Alarcón" en Internet. Lo hace como Director de la Biblioteca Virtual Saavedra Fajardo, Pensamiento Político-Hispánico. Pudiera tener algo de razón, si se refiere al presidente que ha seguido a Maquiavelo y ha gobernado recordando a su abuelo, que era masón, con una memoria histórica poco reconciliadora. 
en tierras lejanas de las Indias, como lo hizo fray Alonso de Veracruz, que llegó a corregir a Francisco de Vitoria ${ }^{103}$. Un paso adelante lo va a dar fray Martín de Córdoba, en su Jardín de nobles doncellas, para formar a Isabel la Católica, cuya lectura le recomiendo a José Luis Villacañas Berlanga, para que vea la influencia de los canonistas agustinos en la formación política y religiosa de España.

\section{Fray Martín de Córdoba y "Notabilis repetitio" sobre la potestad ecle- siástica}

Fray Martín de Córdoba era cordobés y entró en el convento de dicha ciudad, donde permaneció hasta 1420, en que fue destinado a Salamanca, donde llegó a ser el primer catedrático de renombre entre los agustinos. Aunque su nombre completo, según Tomás de Herrera y otros, era Martín Alfonso de Córdoba, él siempre firmó como Martín de Córdoba ${ }^{104}$. Anteriormente habían estado en esa Universidad fray Antonio de Écija, que tenía el grado de Maestro y leyó el libro de las Sentencias en 1411, y fray Juan de Santo Tomás, que era portugués y participó en la reforma de las Constituciones de 1419. El 1 de septiembre de ese mismo año, el general de la Orden, fray Agustín A. Favaroni de Roma, designó estudiantes del convento de Salamanca a fr. Hernando de León y a fr. Juan de Montemayor, lo que indica que ya era casa de estudios, por lo que, el día 4.8.1420, el mismo superior general le dio facultades a fray Martín de Córdoba para leer las Sentencias de Pedro Lombardo en el convento de Salamanca ${ }^{105}$. El mismo prior general, el 25.3.1424, autorizó a Martín de Córdoba para ir a Zaragoza, donde residió hasta 1431. Ese año, en el mes de enero, a instancias del sacrista del papa Eugenio V, el general Gregorio de Rimini, le confirió el título de Bachiller y le dio permiso para ir a la universidad de Toulouse (Tolosa, Francia) donde leyó las Sentencias en 1431-1432. Después de esto, fue promovido al Magisterio en $1436^{106}$. Se encontraba de nuevo en Salamanca,

${ }^{103}$ F. CAMPO DEL Pozo, "Fray Alonso de Veracruz y sus aportaciones al Derecho, como las causas justas e injustas de la conquista", en: Del Tratado de Tordesillas a la doctrina de los derechos fundamentales en Francisco de Vitoria, ed. por Juan Goti Ordeñana, Valladolid 1999, pp. 375-415.

${ }^{104}$ G. De Santiago Vela, Ensayo, II, pp. 89-90. Según el P. Gregorio de Santiago Vela conviene poner sólo Martín de Córdoba para evitar confusiones como ha sucedido al identificarle algunos con Alfonso de Córdoba que también era de Córdoba y llegó a ser profesor de Salamanca en 1508 e introdujo el nominalismo. Ibíd. II, pp. 77-87.

${ }^{105}$ Archivo General de la Orden de San Agustín en Roma, reg. Dd 4, ff. 4r.

${ }^{106}$ G. DE Santiago Vela, Ensayo, II, p. 90. 
como profesor universitario en 1451 y fue elegido vicario general para que siguiese cultivando los estudios en la ciudad del Tormes, donde el convento de san Agustín se había incorporado a la observancia en 1448. Esto le creó problemas que han sido tratados en otro lugar, quedándole tiempo libre para escribir varios tratados, que se conservan, como el Compendio de la Fortuna, el Tratado de la predestinación, Ars predicandi y Jardín de nobles doncellas, que es el que le ha dado más fama, ya que fue amigo del Condestable Don Álvaro de Luna y de Don Juan II, que le propuso para la formación de D. Alfonso y luego de su hermana Isabel, a la que consideró y preparó para ser reina de España. El 7 de junio de 1476 fue nombrado vicario general del convento de Valladolid, donde murió poco después, 5 de julio del mismo año, siendo enterrado en el presbiterio de la iglesia de dicho convento, actualmente convertida en Archivo Municipal ${ }^{107}$.

Se sigue sin noticia del paradero de otros escritos como Lógica et Philosophia, De mystica et vera theologia, Libro de las diversas historias y la Alabanza de la Virginidad. Es posible que aparezca alguno de estos libros, como el manuscrito que vamos a ver, con su contenido y valor sobre la potestad eclesiástica. Últimamente se están haciendo estudios sobre su doctrina, especialmente por su obra "Jardín de nobles doncellas" y la repercusión en Isabel la Católica.

\subsection{El manuscrito de la "Notabilis repetitio" y su contenido}

Al hacer el trabajo sobre "Juristas agustinos de los siglos XIV y XV", en 1970-1971, como se ha observado al principio, el P. Antonio García y García me facilitó el microfilm del manuscrito sobre la Notabilis repetitio que había aparecido en el archivo del cabildo de Córdoba. Este manuscrito procedía de Salamanca según la antigua signatura, y perteneció a Juan Alfonso de Benavente, cuyo nombre aparece con firma autográfica ${ }^{108}$.

En la pieza tercera del manuscrito, se menciona a Buenaventura cardenal. Si se refiere a san Buenaventura, tiene que ser antes de su canoni-

${ }^{107}$ F. CAMPO DEL POZO, "Opúsculo sobre la potestad eclesiástica de Martín de Córdoba” en La Ciudad de Dios, 208 (1995) 663-666, donde pueden verse sus escritos y los que están publicados.

${ }^{108}$ A. GARCía y GARCía, y otros, Catálogo de los manuscritos e incunables de la catedral de Córdoba, Salamanca 1976, p. 266, donde consta sus antiguas signaturas: A. 412; 134, luego ms. 128. El Códice tiene 26 piezas de las que la Notabilis repetitio ocupa el n. 25 . Se agradece al P. A. García la atención de facilitarme el microfilm, que antes había entregado a Manuel Villegas. Éste, a su vez, lo pasó al P. Fernando Rubio, que comenzó a trascribirlo y me entregó parte de la copia de lo que tenía hecho, porque se encontraba con algunas dificultades sobre las citas y las fuentes de índole canónica. 
zación el 14 de abril de 1484, a no ser que se refiera al cardenal Buenaventura Baduario agustino. Está escrito en letra gótica cursiva, de la misma mano todo lo que se refiere a la Notabilis repetitio. En el resto hay varias manos con cuadernillos de 12 folios y reclamos. La foliación es arábica y reciente. Rúbricas en rojo, lo mismo que las iniciales y los calderones. "encuadernación medieval, en tabla, cubierta de cuero, con dibujos mudéjares. Dos cierres caídos. Tejuelo: antiguas signaturas"109.

La Notabilis repetitio era un género literario, canónico y jurídico. Los Notabilia proceden de las observaciones puestas al Decreto de Graciano para llamar la atención del lector sobre algo importante, que merece la pena ser destacado. Estas llamadas se hacían mediante las palabras Nota quod, Notandum quod, etc. Luego se toma en sentido más amplio y se aplica este arte o género como una regula iuris, un capítulo, dicho o sentencia con una argumentación, como una tesis breve o una tesina actual. Sobre el origen y evolución de los Notabilia a través de los códices medievales de los siglos XII y XIII hay buenos estudios, como el que ha hecho Stephan Kuttner, como algo distinto de los Casus y los Brocarda.

El texto comienza con dos palabras en mayúscula QUOD AUTEM, indicando su pertenencia al género de los Notabilia con su argumentación. La palabra Repetitio hay que tomarla como "repetición" según consta en los jurisconsultos romanos, recapitulación, reclamación o resumen, en este caso sobre la "potestad eclesiástica". Era lo que se llamaba también disputatio o lección magistral, que dieron origen a la lectio coram de las universidades pontificias y a la prelección que tenían los jesuitas para demostrar su capacidad y competencia. Los Notabilia eran diferentes de los casos, que vienen a ser como una ilustración o aclaración para pensar sobre una cuestión, mientras que los Brocarda eran el enunciado de los principios generales del Derecho añadiendo el pro y el contra de las soluciones. En aquella época existieron autores que hacían glosas al Decreto o a las Decretales. Las glosas eran comentarios o exposiciones exegéticas, mientras que las summas eran exposiciones sistemáticas sin exégesis, que era lo característico de la glosa. En los Notabilia repetio se trataban también problemas jurídicos y cuestiones, que no estaban solucionados expresamente por el Derecho y necesitaban aclaración, como sucede en este opúsculo de Martín de Córdoba. Se hace aquí un pequeño excursus para aclarar estos conceptos canónicos.

${ }^{109}$ Ibíd., p. 266.

${ }^{110}$ S. KutTNER, Repertorium del Kanonistik (1241-12345) Prodromus corporis glossarum, I. Cita del Vaticano 1937, pp. 228-240. 
La Notabilis repitio de Martín de Córdoba consta de tres capítulos cuyo contenido se esboza en el primer párrafo al afirmar "que para bien de la Iglesia se requiere una doble potestad, que va a investigar por tres vías: primera en sí, segunda en orden al acto y tercera con relación al objeto" 111. Esto se desarrolla en el capítulo primero, cuyo título no aparece, acudiendo a la Biblia, especialmente al nuevo Testamento, Aristóteles, san Agustín y Hugo de san Víctor, llegando a la conclusión de que la potestad terrena está subordinada a la espiritual, y admitiendo que el sacerdote debe someterse a veces también a la potestad terrena, como la carne debe obedecer al espíritu y viceversa ${ }^{112}$.

En el capítulo segundo, se pretende demostrar que "toda potestad viene de Dios, pero de un modo inmediato, sólo la del Papa"; a los príncipes es dada para el ministerio. Lo desarrolla ampliamente haciendo referencia a la doctrina de las dos espadas. Incluso se plantea la posible justificación de los imperios paganos y su permisibilidad por parte de Dios, la necesidad de la pena y el castigo, etc. ${ }^{113}$

En el capítulo tercero, se plantea la cuestión difícil y antigua de que "la potestad espiritual precede a la temporal en el tiempo y en dignidad". Antes que el papa hubo reyes e imperios. Distingue posibles estados de distinta naturaleza, antes y después del pecado, acudiendo a la historia del pueblo de Israel y al Imperio Romano. Hace un paralelismo y antítesis entre Adán y Cristo. Abel y Melquisedech fueron símbolo del sacerdocio de Cristo y de la potestad sacerdotal, mientras que Caín ejerció la potestad dominativa. Trata también otras cuestiones para concluir que el papado comienza con san Pedro, que fue Vicario de Cristo; pero el papado "en cuanto al oficio de ejecución plena en lo temporal y espiritual, comienza por el beato Silvestre" $" 114$.

\subsection{Valor de este opúsculo sobre la potestad eclesiástica y civil}

Este opúsculo da a conocer cómo estaba el problema de la potestad eclesiástica en el siglo XV con sus antecedentes. Distingue la potestad de orden y la de jurisdicción, que se hallaba implícita en ciertas instituciones laicales, como los antiguos archidiáconos, los arcedianos y arciprestes, etc. Un simple fiel cristiano podía ser nombrado para ocupar ciertos cargos u

\footnotetext{
${ }^{111}$ Archivo del Cabildo de Córdoba, 128, f. 328r.

${ }^{112}$ Ibíd., ff. 230v-331r.

${ }^{113}$ Ibíd., ff. 331r-335.

${ }^{114}$ Ibíd., ff. 335-337.
} 
oficios con potestad de jurisdicción, sin tener la de orden, aunque no pudiesen ejercer los actos para los que se requería la potestad de orden. Se llegó a hablar de potestas sicut ministerium legis ${ }^{115}$.

Este opúsculo tiene gran valor para ver cómo se discutía sobre el alcance y precisión de las potestades, que requería el mismo bien de la iglesia y cómo se configuró la potestad eclesiástica en sus dos clases: la de orden y la de jurisdicción. Aparece esbozada la teoría de que la potestad de orden y la de jurisdicción tienen un origen distinto, aunque para la ejecución de ciertos actos de jurisdicción debe preceder la de orden. Lo mismo sucede con la potestad temporal y la espiritual, aunque ambas proceden de Dios y le pasan a san Pedro, como Vicario de Cristo y sus sucesores que vienen a formar un conjunto o algo unitario. Toda potestad de jurisdicción en la iglesia formalmente tiene su fuente formal en el papa ${ }^{116}$.

En las diócesis se puede nombrar obispo a un laico, como sucedió con san Ambrosio, que tendría jurisdicción para hacer visita pastoral y nombramientos, aunque no puede realizar actos que requieran la potestad de orden hasta que no sea ordenado o consagrado. Esto se seguía dando en el siglo XIX, como sucedió con el P. Antonio Burbano, primer obispo electo de Pasto (Colombia), donde sin consagración, hizo visita pastoral y tomó decisiones jurisdiccionales ${ }^{117}$.

Si Martín de Córdoba leyese el c. 129 del actual Código de Derecho Canónico, se alegraría del párrafo 10: "De la potestad de régimen, que existe en la Iglesia por autoridad divina, y que se llama también potestad de jurisdicción, son sujetos hábiles, conforme a la norma de las prescripciones del derecho, los sellados por el orden sagrado"; y al mismo tiempo se sorprendería cuando en el párrafo $2^{\circ}$ se dice: "en el ejercicio de dicha potestad, los laicos pueden cooperar a tenor del derecho". En el siglo XV podían tener potestad de jurisdicción los laicos, no sólo cooperar.

\section{Conclusión}

Los escritos de los canonistas agustinos españoles de los siglos XIV y $\mathrm{XV}$ no se pueden comprender si no se tiene en cuenta la doctrina de san Agustín, y los canonistas agustinos italianos de los siglos XIII y XIV. San

\footnotetext{
${ }^{115}$ Ibíd., f. 328.

${ }^{116}$ Ibíd., f. 232r: "Jurisdictionis formaliter residet in Papa".

${ }^{117}$ F. CAMPO DEL Pozo, "Fray Pedro Antonio Burbano primer obispo electo de Pasto", en Archivo Agustiniano, 79 (1995) 115-135.
} 
Agustín procuró solucionar los problemas acudiendo a la Biblia, a los concilios y las decisiones del Romano Pontífice. Aunque él puso las bases de un Derecho natural de contenido mudable, en la Edad Media, los canonistas y juristas agustinos, como los de la Escolástica, hablaron de principios primarios y secundarios de la ley natural, que admitían cierto cambio. Es aleccionadora la doctrina de san Agustín sobre la ley eterna, natural y positiva, sobre todo cuando afirma: "El legislador temporal, si es sabio y bueno, consulta a la ley eterna, que ningún hombre puede juzgar, para que de acuerdo con sus normas inmutables, pueda conocer aquello que en ese momento conviene mandar o prohibir"118.

En la Edad media se daba cierta secularización; pero predominaba el sentido religioso de la conciencia cristiana sobre las leyes. Se tenían en cuenta los valores religiosos. Hoy vivimos en una sociedad más secularizada en la que no todos reconocen a la ley eterna, que ya admitían los filósofos griegos y los juristas romanos, con la búsqueda y la formulación de la ley natural que garantice la legitimad de las leyes positivas. Los canonistas agustinos de los siglos XIV y XV procuraron seguir la doctrina de san Agustín y se dieron cuenta de que cuando el Derecho natural es negado y la sola voluntad del legislador hace leyes, según sus conveniencias, entonces el legislador ya no es intérprete de lo que es justo y bueno, atribuyéndose prerrogativas de ser el criterio último de la justicia. Esto lleva a considerar que no es verdadero matrimonio la unión de dos hombres por el origen de esta institución de un hombre y una mujer, y porque falta el munus matris, que da el nombre a "matrimonio". El matrimonio gay es algo contradictorio; como lo es también eliminar la pena de muerte y luego legalizar el aborto. Contra esto protestaría valientemente san Agustín, como lo hizo con la carta 138 dirigida a Marcelino y las cartas 133 y 155 a Macedonio, vicario imperial en África, ofreciendo "una explicación coherente y teórica de cómo los políticos cristianos deben abordar las decisiones éticas", en lo que hay un mensaje para los obispos, laicos y políticos cristianos de la edad media y de hoy ${ }^{119}$.

San Agustín supo conjuntar la Religión cristiana con la Filosofía griega y el Derecho Romano dando origen, especialmente con su Ciudad e Dios, a la formación de la Cultura cristiana de Occidente, y poniendo las bases de lo que se llamó el Sacro Imperio, como lo deseaba Carlo Magno. En esto pensaba también Thomas Mann cuando hablaba de una Europa como pa-

${ }^{118}$ De vera religione, $31,58$.

${ }^{119}$ R. Dodaro, "Obispos, laicos y política según san Agustín”, en Estudio Agustiniano, 40 (2008) 468-506. 
tria común. Lo que era un proyecto deseado se ha hecho realidad en la Unión Europea con una Constitución, donde se omite una referencia al Cristianismo.

En este homenaje al profesor Rafael Navarro Valls se conjuntan también tres clases de estudios: sobre la Religión, el Matrimonio y el Derecho con un abanico, que recoge también lo que hoy llamamos "globalización" con una recopilación del pasado y del presente mirando hacia el futuro del siglo XXI. Esto se vislumbra ya en el primer estudio de las "Relaciones entre Estado y Religión", de Jaime Bonet Navarro titulado: "Presencia y actuación de la Iglesia católica en la sociedad internacional"120.

Tienen actualidad los textos comentados de los canonistas agustinos de los siglos XIV y XV, especialmente la Notabilis repetitio de Martín de Córdoba sobre la potestad eclesiástica, por ser uno de los estudios más profundos y serios de su época, en la que los laicos (católicos) tenían más participación en la vida jurisdiccional de la Iglesia. Dio su mayor talla como escritor y orientador de los políticos en "Jardín de Nobles doncellas, dedicado a Isabel la Católica, a la que consideró tan digna de regir o de gobernar, igual o mejor que los hombres, pudiendo servir de ejemplo y modelo. Por cuatro veces la considera futura reina de España, cuando lo era sólo de Castilla y León. En su opinión Isabel la Católica tenía un evidente y legítimo derecho a gobernar, no por sus títulos dinásticos sino por su linaje y ejemplaridad de gobernar, en su reino y en su casa. Le dice: "procure la cristianísima Princesa, cuando tuviere hijos, que sean criados por amas devotas y católicas, que les nombren a Jesús, a Santa María y a San Miguel"121. Entre los libros de la reina estaban De civitate Dei (Ciudad de Dios de san Agustín en latín, que ella sabía), De regimine Principum de Egidio Romano (Del regimiento de los Príncipes), junto con otros autores de los siglos XIV y XV, que le había recomendado Martín de Córdoba ${ }^{122}$. Esto tuvo también su proyección en el Nuevo Mundo y en las Indias orientales.

Entre los Estudios en homenaje a Rafael Navaro-Valls hay muchos datos novedosos como lo referente "a la legalización del partido comunista" y cómo se llevó a cabo la actuación de Santiago Carrillo por medio de Teodulfo Lagunero ante D. Aurelio Menéndez Menéndez, que era ministro del II $^{\circ}$ Gobierno de la Monarquía y I ${ }^{\circ}$ del Presidente Adolfo Suárez (1976-

${ }^{120}$ Estudios en homenaje al Profesor Rafael Navarro Valls, I, pp. 101-127.

${ }^{121}$ M. DE CóRdobA, Martín, Jardín de nobles doncellas, ed. por Félix García, Madrid 1953, p. 163.

${ }^{122}$ F. CAMPO DEL POZO, "Isabel la Católica, fiel hija de la Iglesia y la Hispanidad”, en Estudio Agustiniano, 39 (2004) 541-546. 
1977), especialmente lo que sucedió el 25 de agosto de $1975^{123}$. Como éste hay otros trabajos que hacen interesante esta obra con muchos estudios complementarios sobre cuestiones actuales de lo que se llama Derecho Eclesiástico del Estado en España y su proyección fuera de nuestras fronteras y de Europa, como EE.UU. y la religión islámica.

Los canonistas y juristas agustinos nos pueden ayudar no sólo a comprender el pasado sino también a forjar el provenir con la defensa de los derechos humanos y los valores cristianos, porque, como dijo Miguel de Unamuno, "la religión católica ha influido y sigue influyendo en el modo de ser y de pensar del pueblo español, tanto más que su lengua, su legislación, su historia, etc." ${ }^{124}$.

${ }^{123}$ A. MenÉndez Menéndez, "Algunas omisiones en los estudios sobre la transición política española (1976-1977)" en Estudios en homenaje a Rafael Navarro-Valls, II, pp. 3.3673.368 .

${ }^{124}$ M. DE UnAmuno, "Educación" en La dignidad humana, $5^{a}$ edic., Espasa Calpe, Colección Austral, Madrid 1961, pp. 79-80. D. Miguel de Unamuno creía en Dios afirmando: "si creo en Dios, o, por lo menos creo creer en Él, es, ante todo, porque quiero que Dios exista, y después, porque se me revela, por vía cordial, en el Evangelio, y a través de Cristo y de la Historia. Es cosa de corazón". "Mi religión" en Obras selectas, 3 edic. Madrid 1956, p. 255. Esto está dentro del pensamiento agustiniano, al ver a Dios dentro de uno mismo, en el corazón, donde está escrita ley natural. 